Acta Crystallographica Section C

Crystal Structure

Communications

ISSN 0108-2701

Editor: George Ferguson

\title{
Potassium Diaqua(ethylenediaminetetraacetato)ytterbate(III)
} Pentahydrate

N. Sakagami, J.-I. Homma, T. Konno and K.-I. Okamoto

This electronic document was scanned from an archival copy of material deposited to accompany a paper published in an IUCr journal. In many cases the only accessible copy was a microfilm of a poor-quality original. 


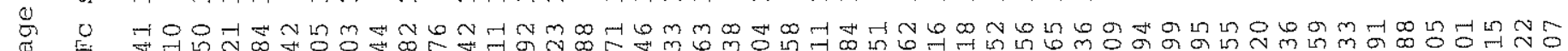

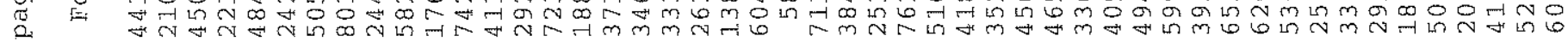

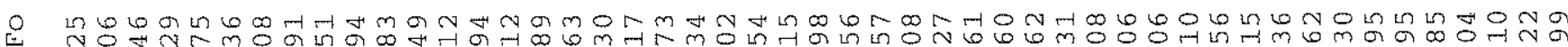

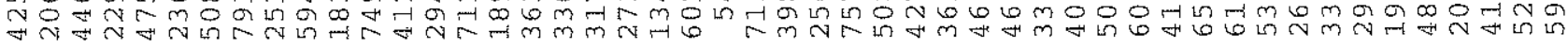

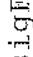

ด్ㅐㅁㅠ क 600 H

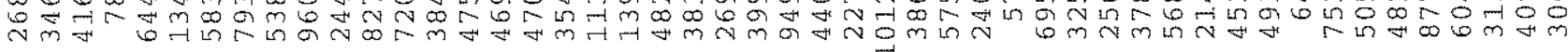
மெ m m

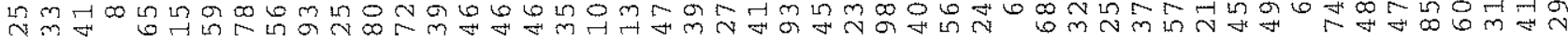
बip

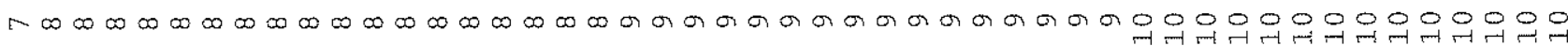
0000000000000000000000000000000000000000000000000

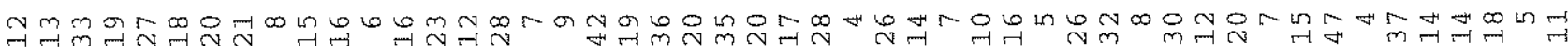
सhm m

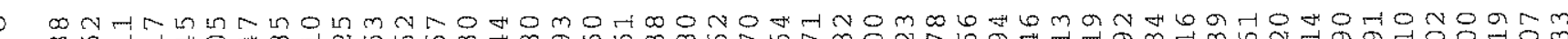

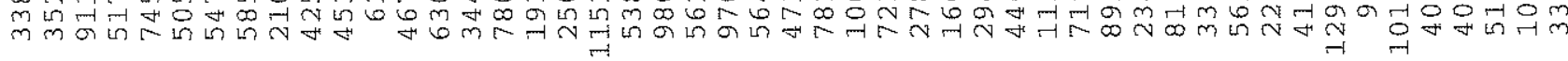
H OHNm

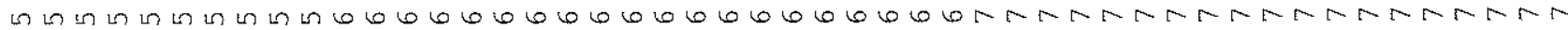
0000000000000000000000000000000000000000000000000

क्ञ

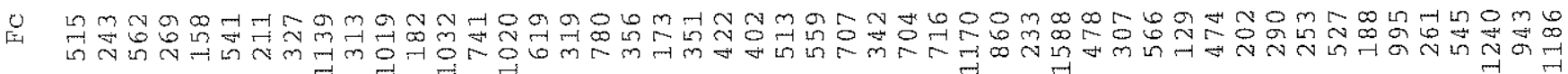

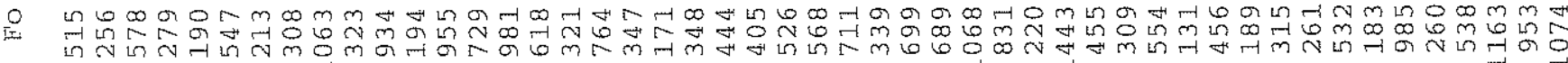
- OGDN य F 000000000000000000000000000000000000000000000000

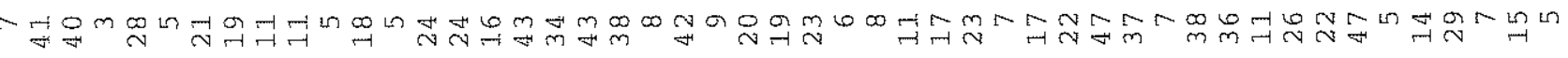

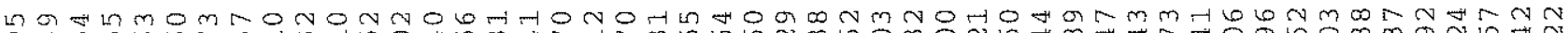

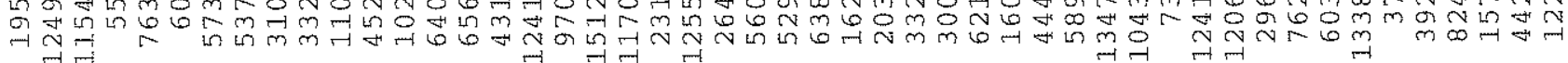
N I OW

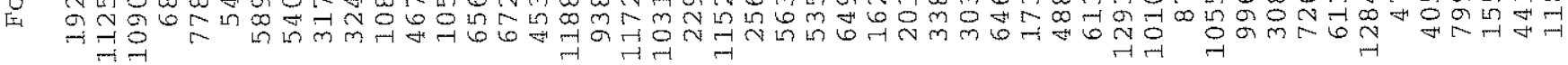

-

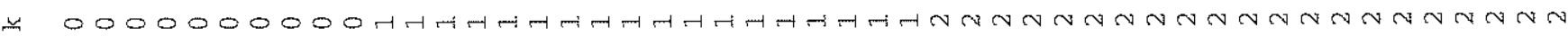
I 000000000000000000000000000000000000000000000000
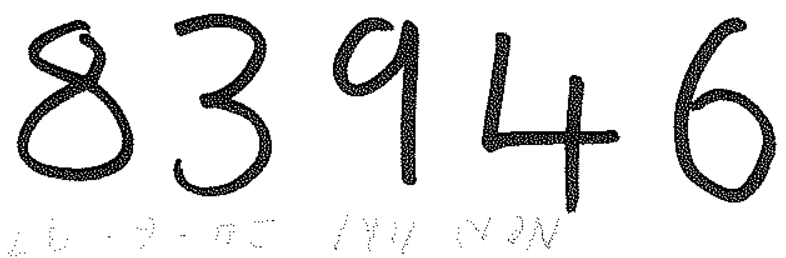


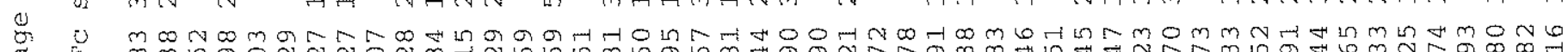

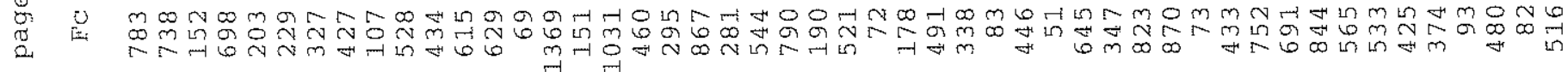

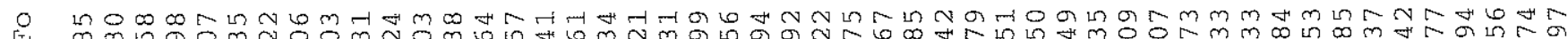

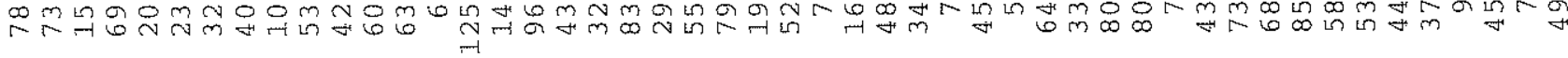
सn 6.

H

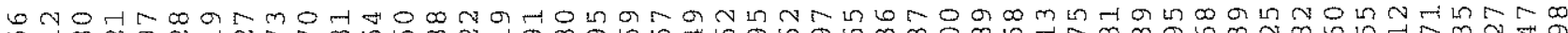
m,

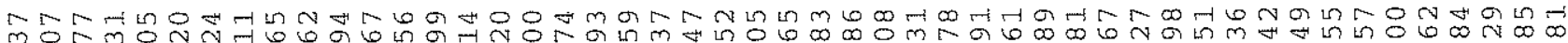

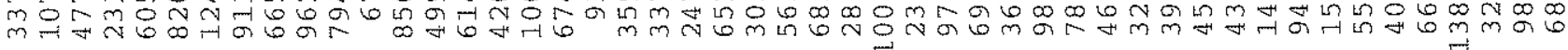
Op

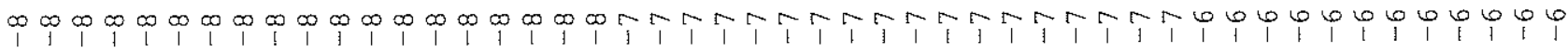

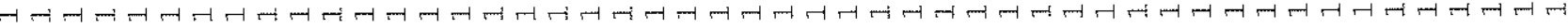

윰ㄱㅁ Mㅐ

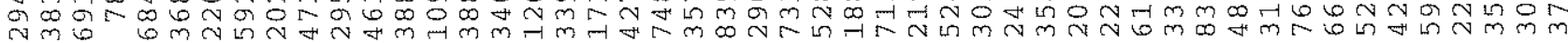

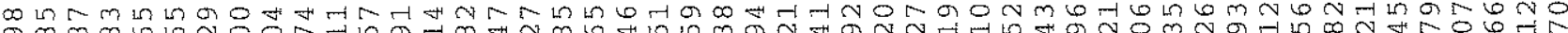

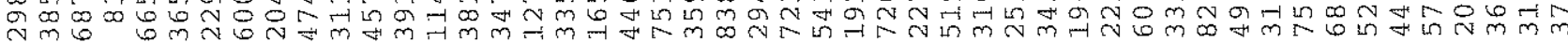
bi

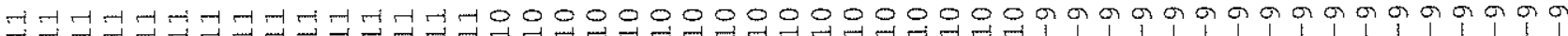

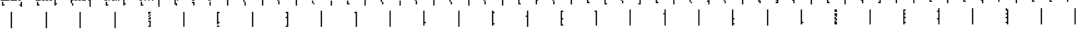

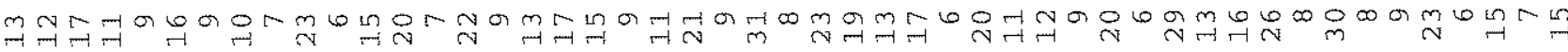

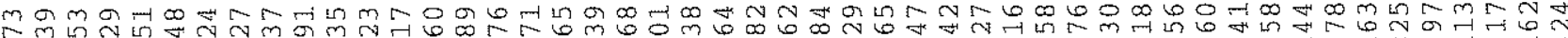
m m

O

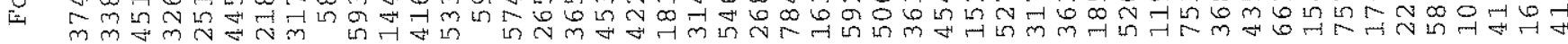
HONm

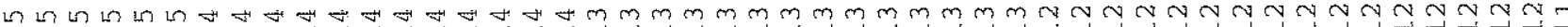
त्र मન

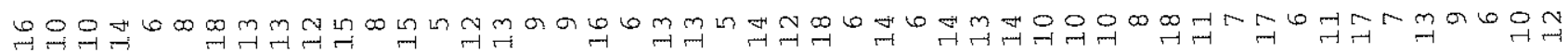

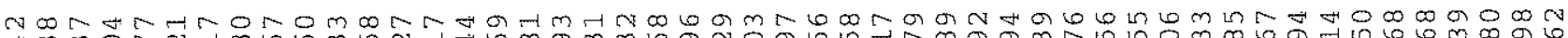
出

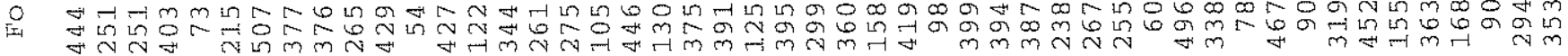

H HNm स⿴囗十

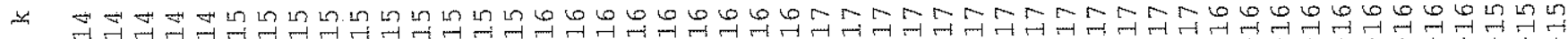


S $\quad$ S

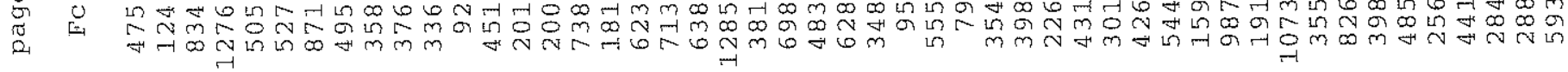

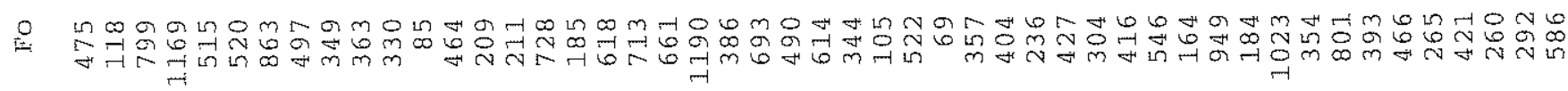

$\rightarrow$ TM

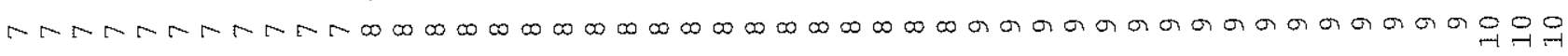

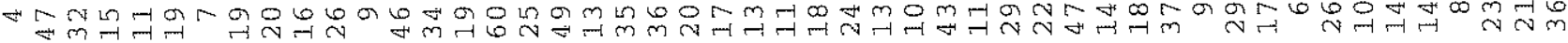
\#mLr

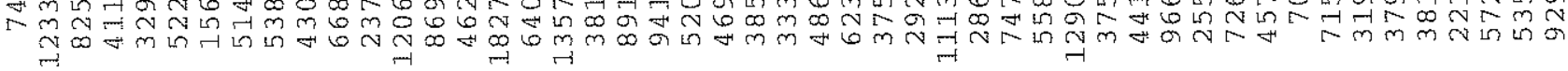

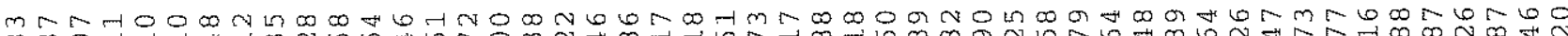

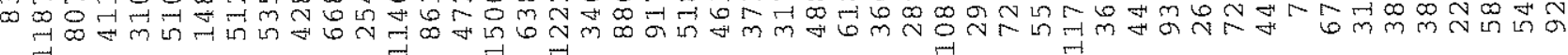
Nmmbrom

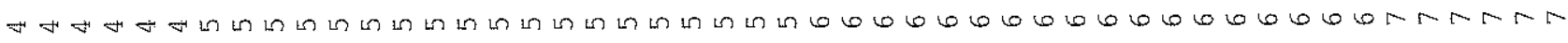

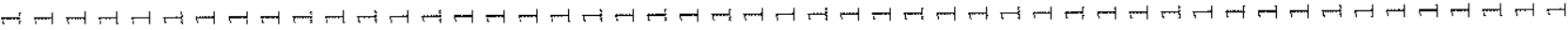

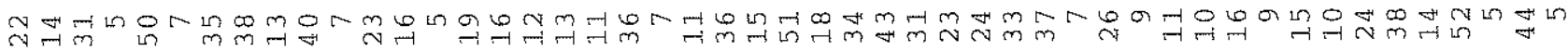
패

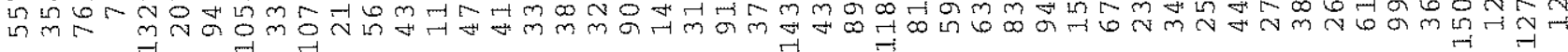

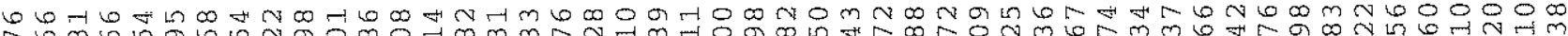

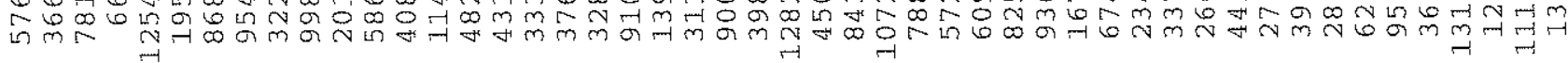
NNM

m

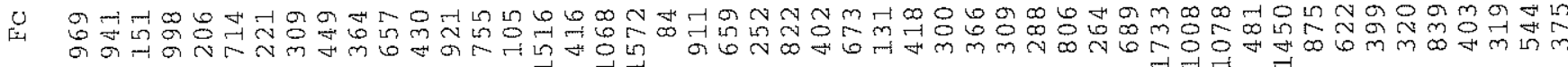

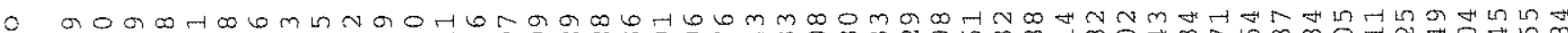

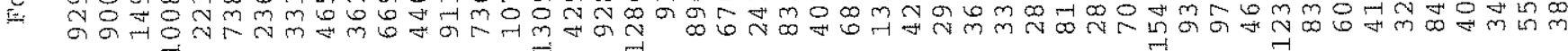
HNm th H. -1

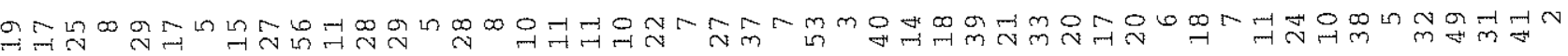

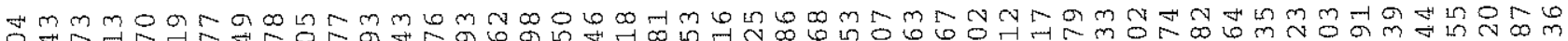

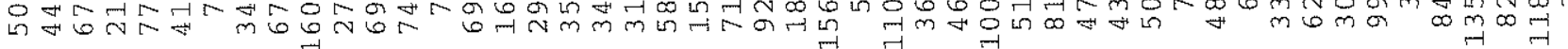

에패 न गु

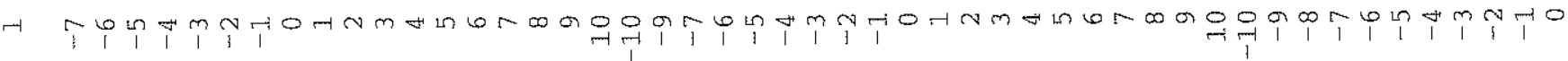

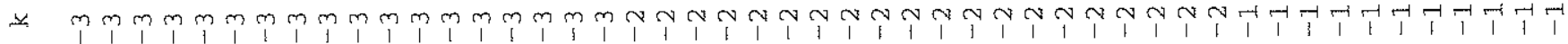


G U N ⿷ 퍼

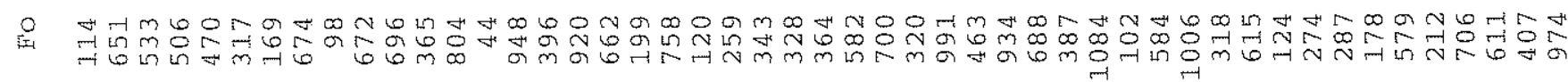
- m m m n m

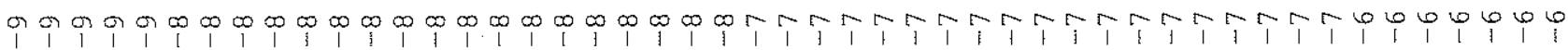

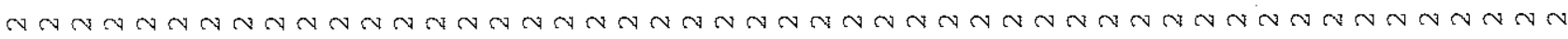

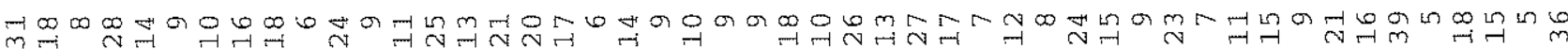

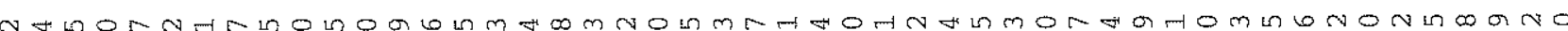

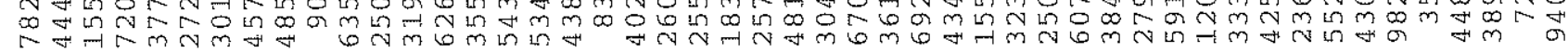

कता

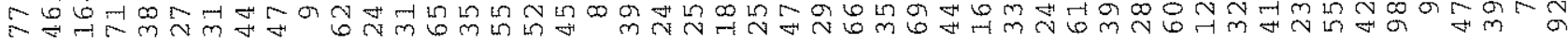

它 5 TOHCH

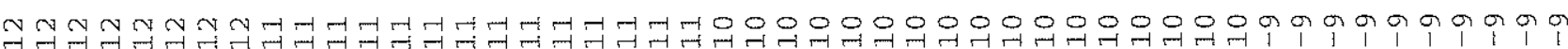

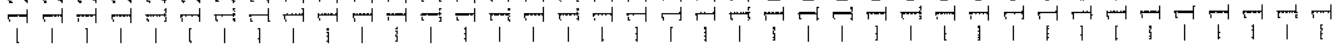

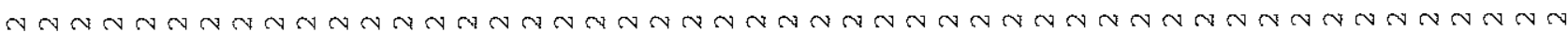

त्र कm

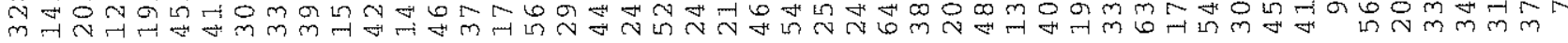

mm

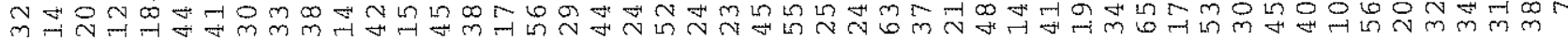
OmNm

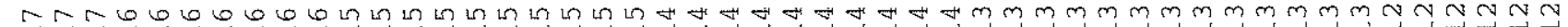

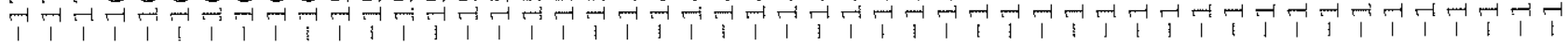

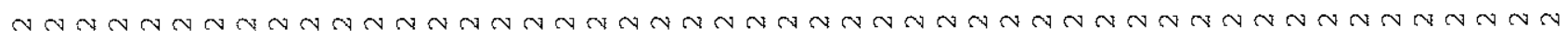

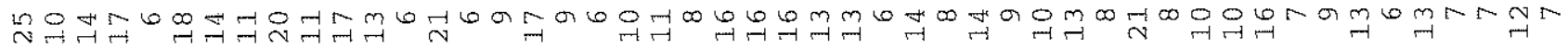
U

- HWH ت

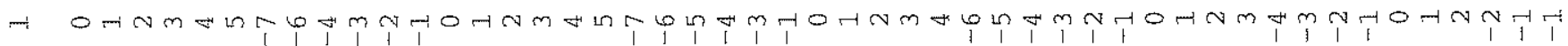
ب mmmmmm

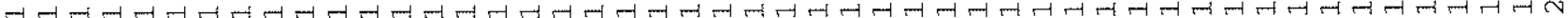

दा जी U Nm

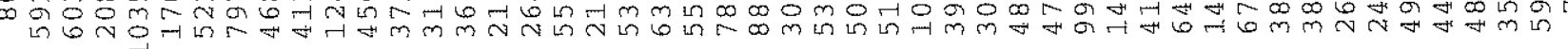

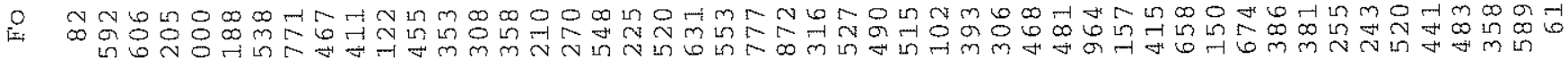
तl -

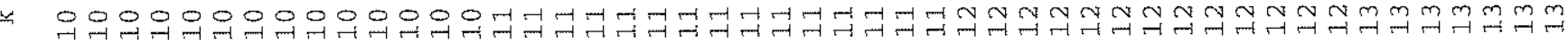

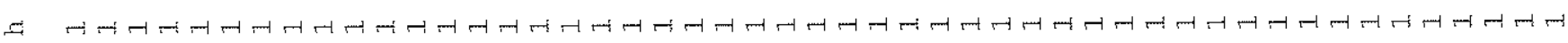




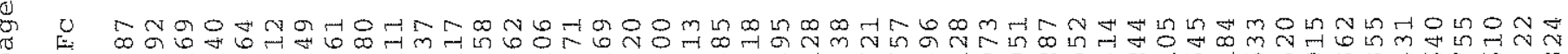
2. $\quad$ N

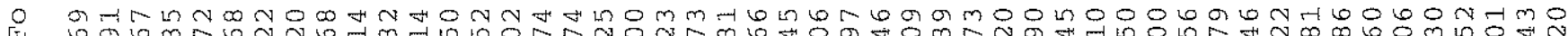

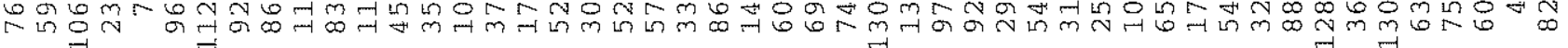

H

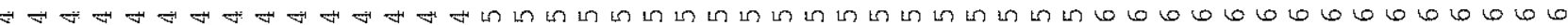

ris

응

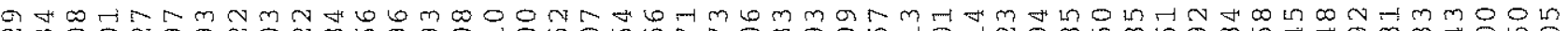
N स

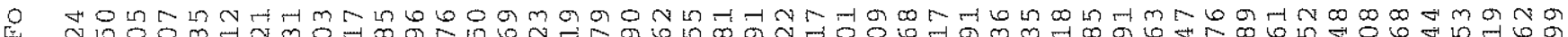

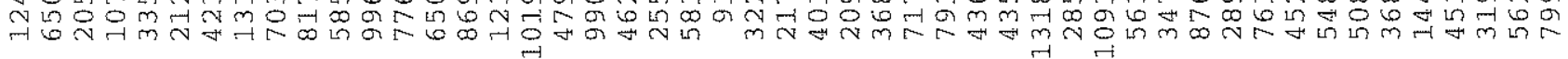
- $\mathrm{x}$ -

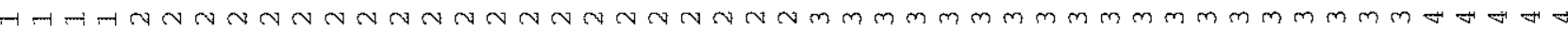

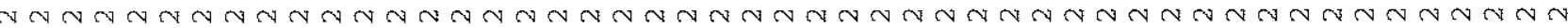

हु:

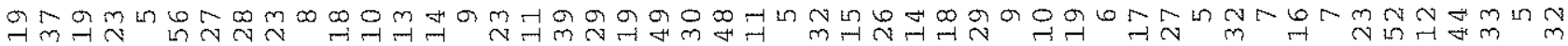

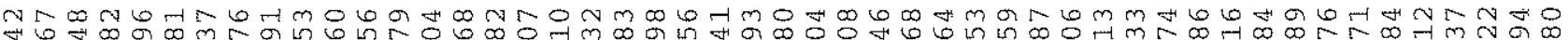

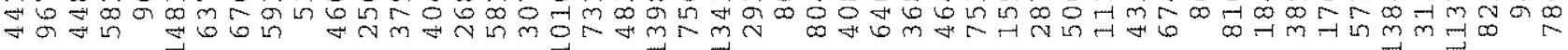

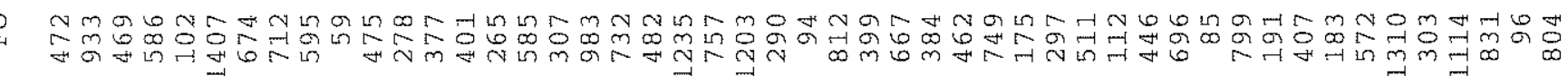
- N

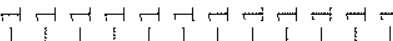

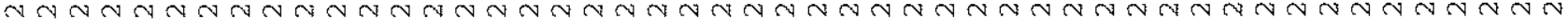

बल

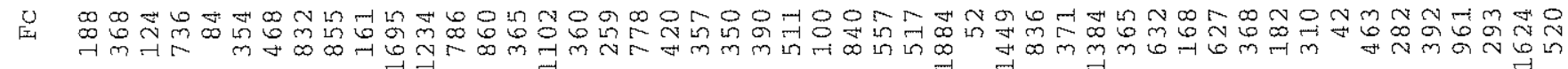

O W

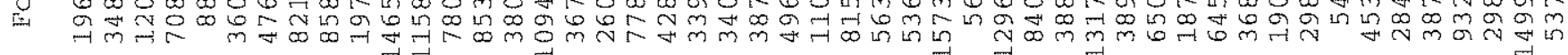
ब유 mmmmmmmmmmmmmmmmm mm

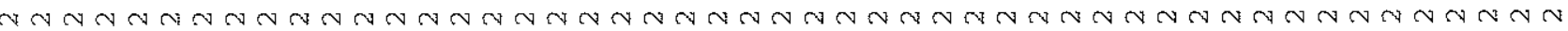

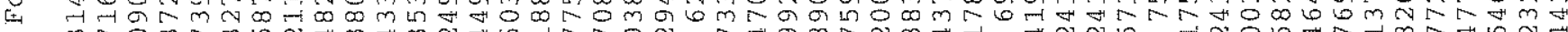

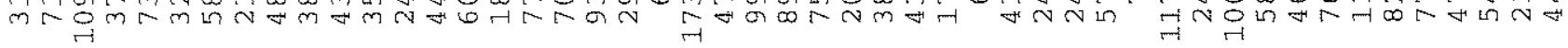

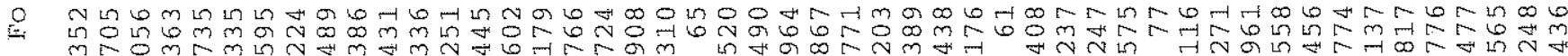
m

$\rightarrow$, ×

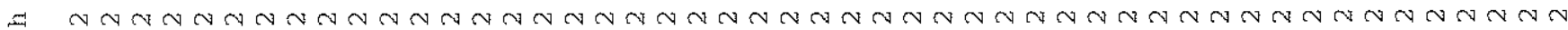


G

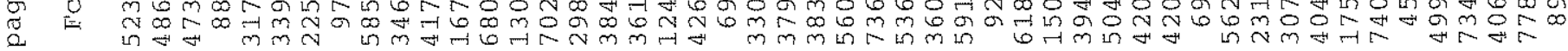

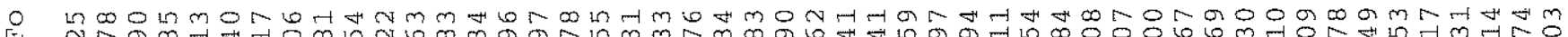

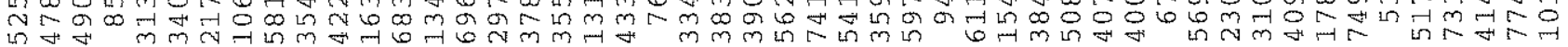

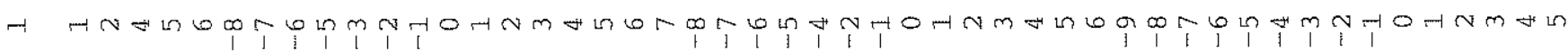

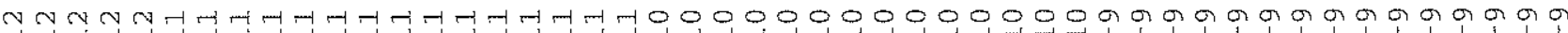

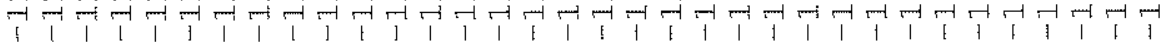

다멕 का

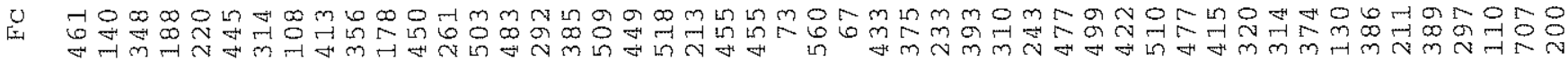

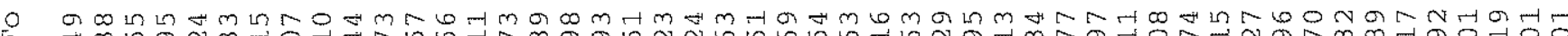

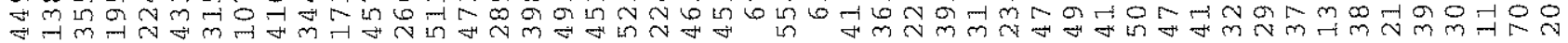

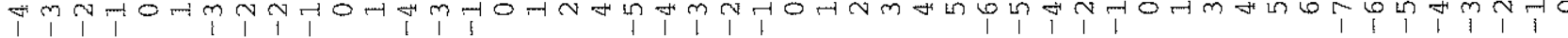

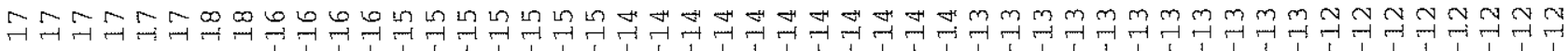

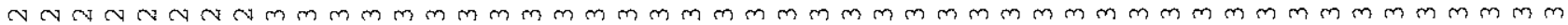

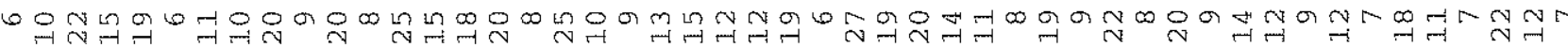

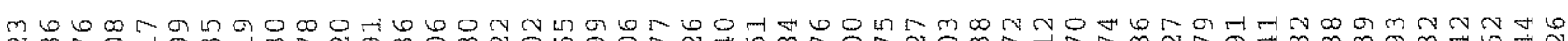

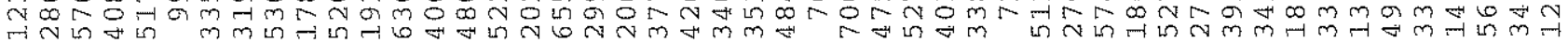

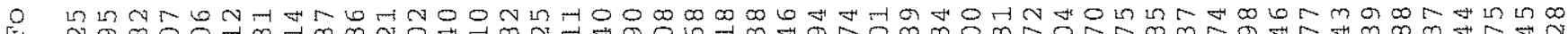

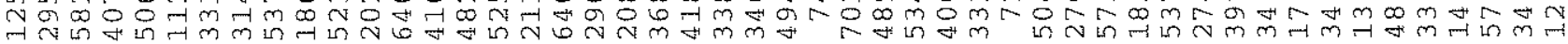
OHNm

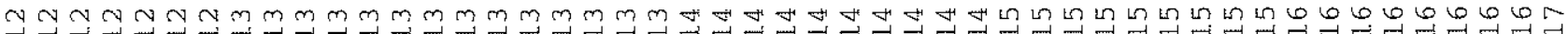

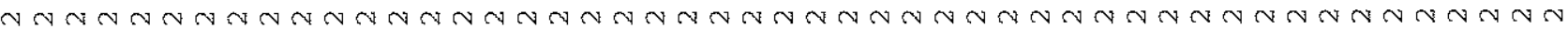

西;

m HONGH

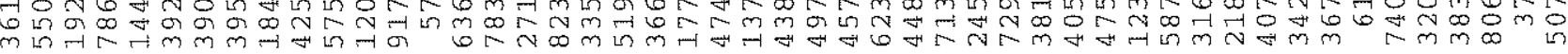

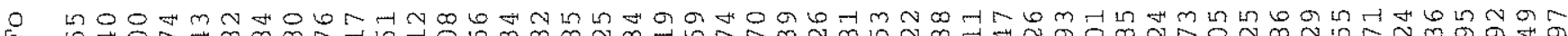
玨 H W Mm स

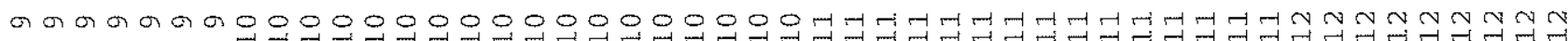

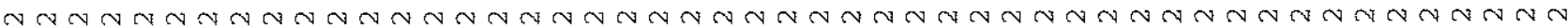
-

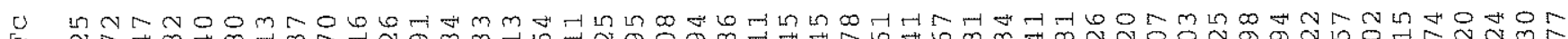

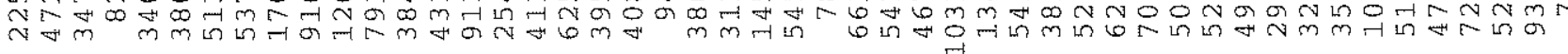

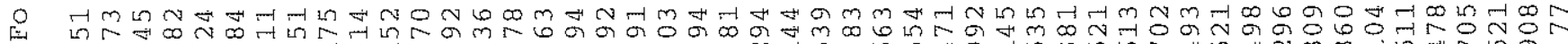
궘

- $\begin{aligned}-1 \\ \text { m }\end{aligned}$ w 0 ow 


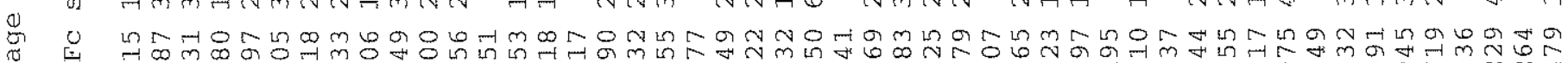

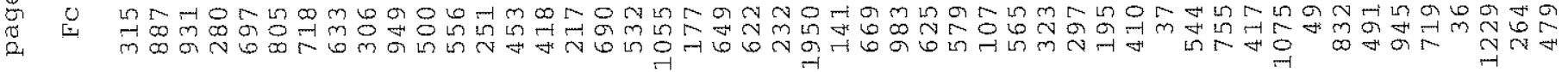

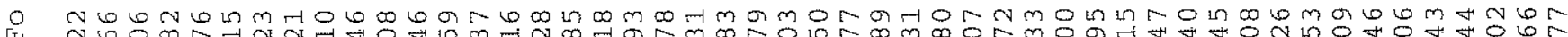
mo

W

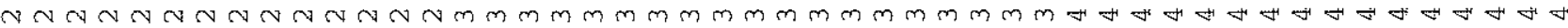

م सr

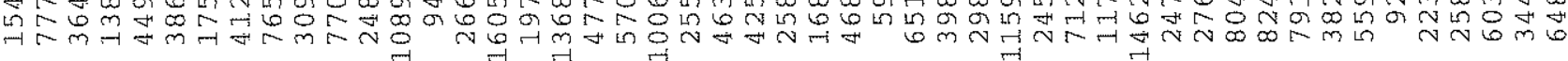

மூீ丨ు 可 पn

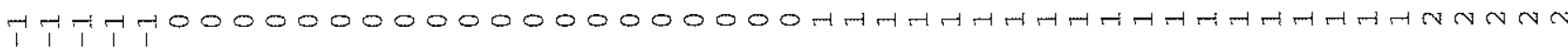


F. m क

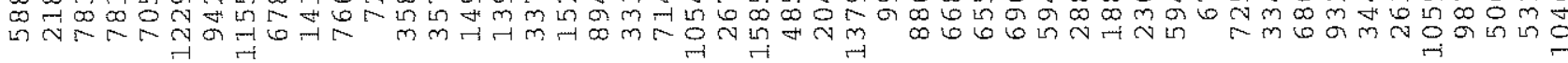

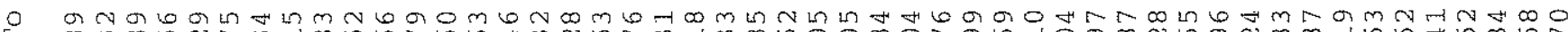
m

mmmmmmmmmmmmmm

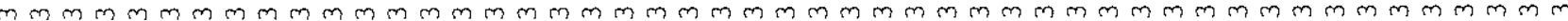

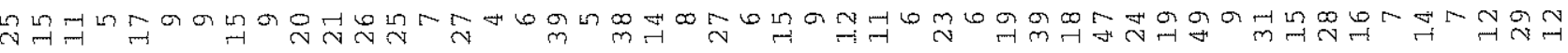

0

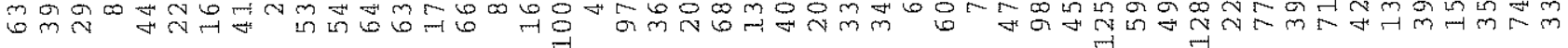

- NHOG Бु

तm

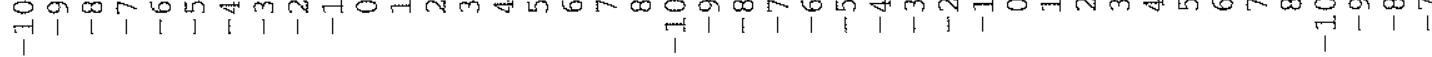
年 пмm

हु)

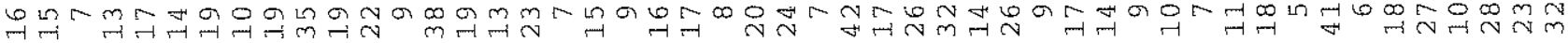
แดm

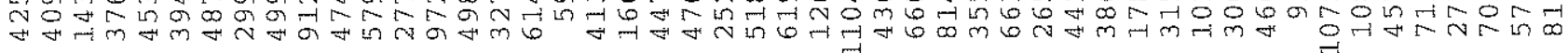

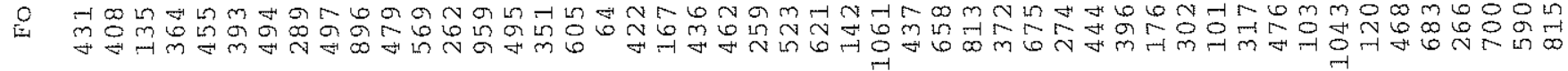
H om - T,

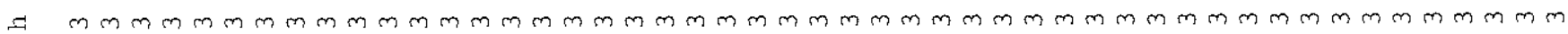


G o bm a ․․

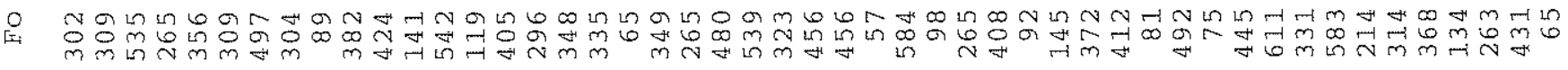

H m m i 4)

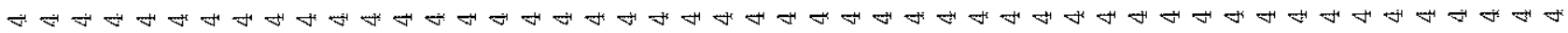

管

क U ब

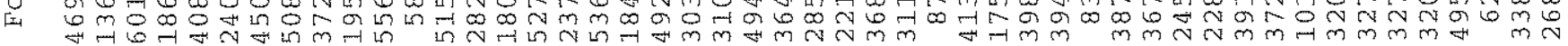

O L

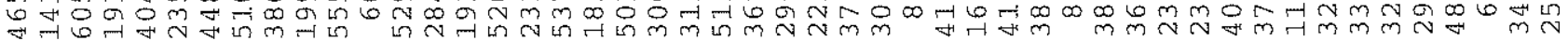

-

mmmmm

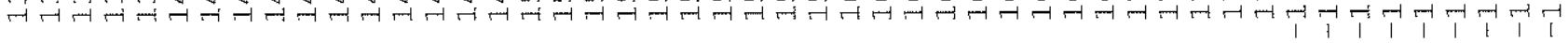
mmm

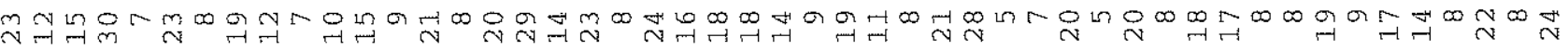

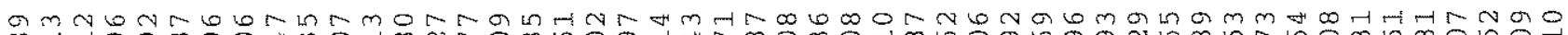

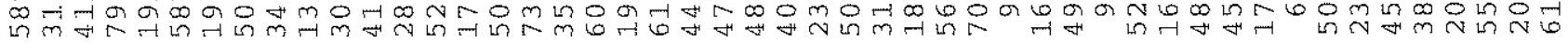
처

- mi

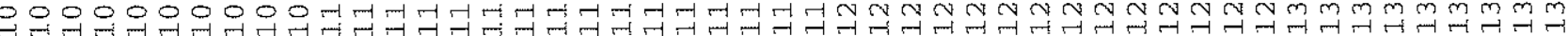

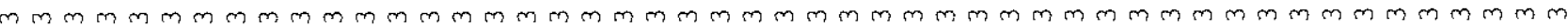

in

퍽에에 L

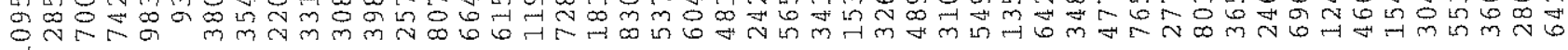

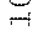

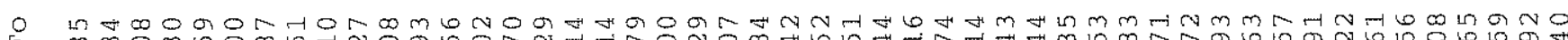

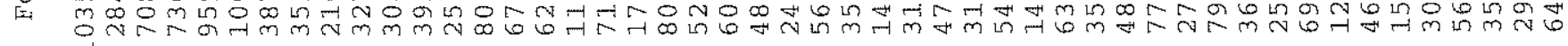
T) M WhN-NMNRЕ तु 0 의

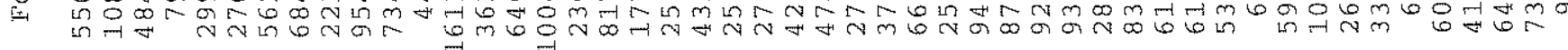

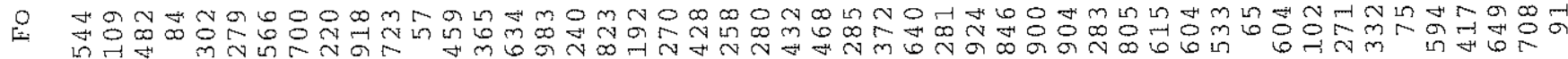
n

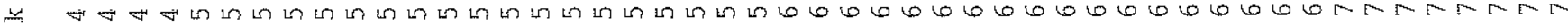


G $\quad$ (1)

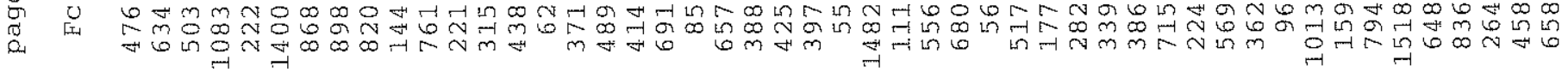

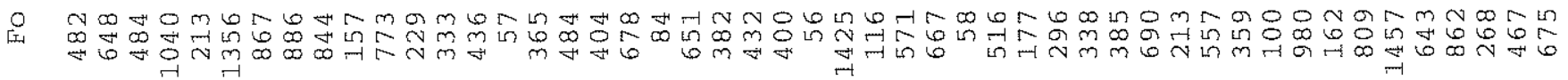

-

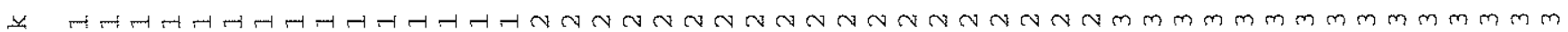

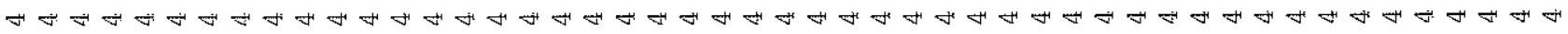

$\frac{1+1}{6}$

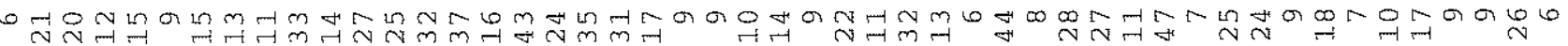

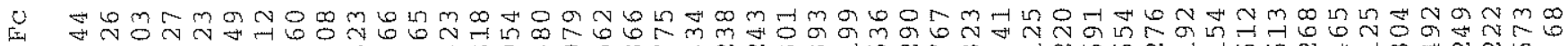

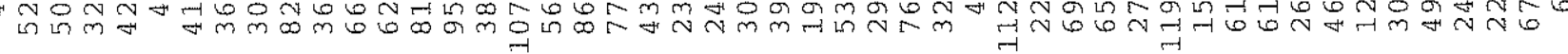

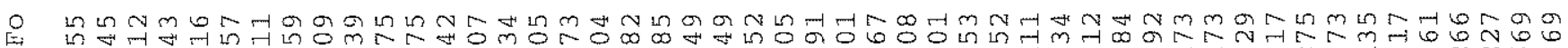
फ

$\rightarrow$ m

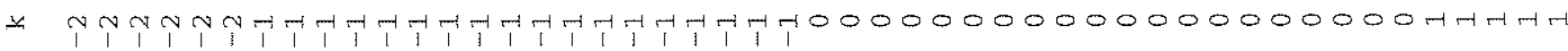

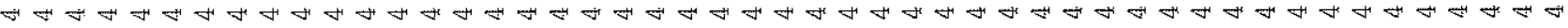

ix

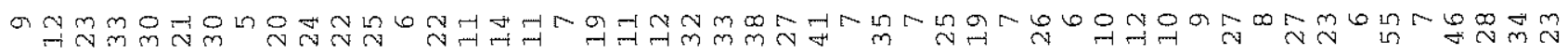

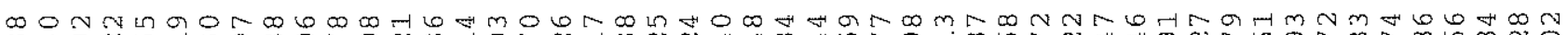
क অ

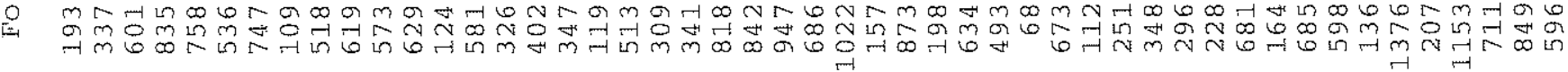

H $\underset{l}{\mathbf{l}}$

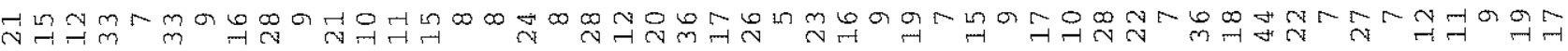
m N जी

O 6 Nmm घ.

$\rightarrow$ म

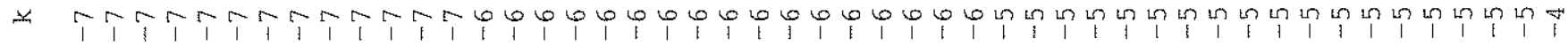
ᄃ III

-

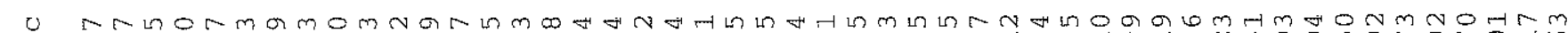

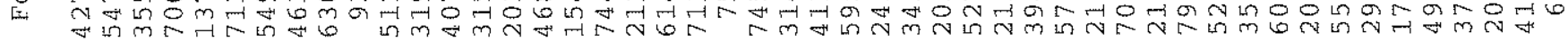
0
\#

-

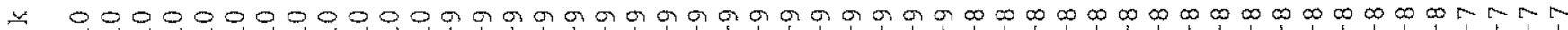

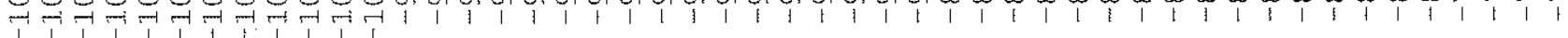




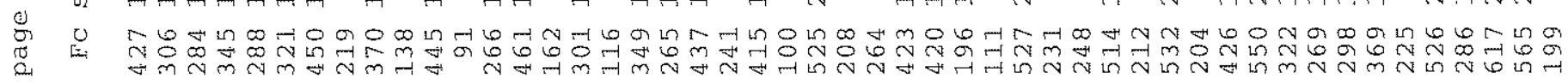

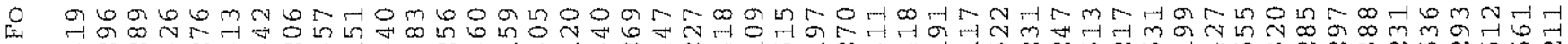

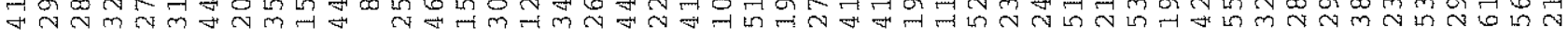

$\rightarrow$ Tr

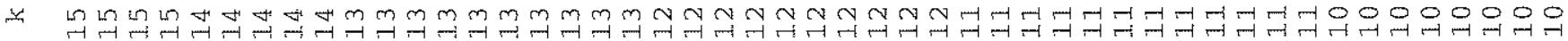

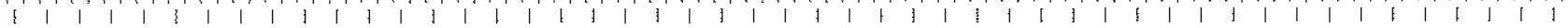

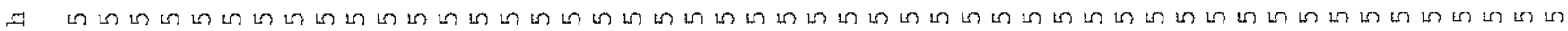

品

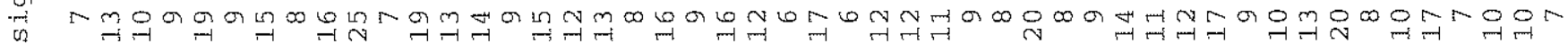

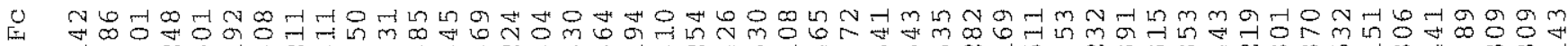
메

O L

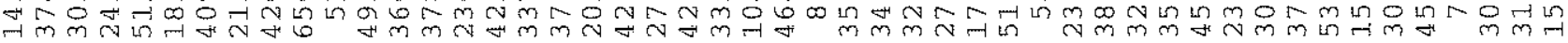

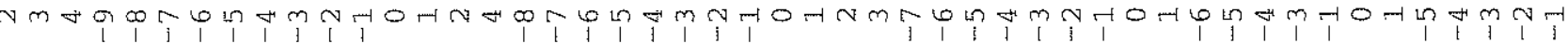

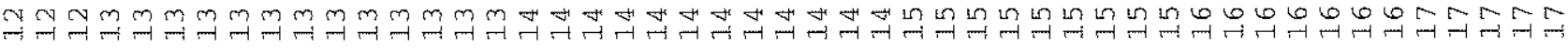

규매 ดा

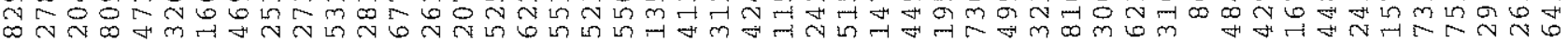

개배에에 क्্

-

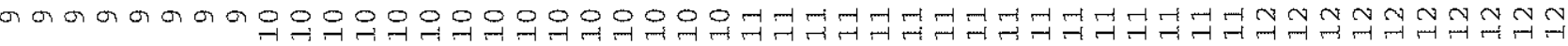

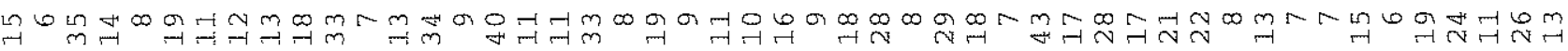

0

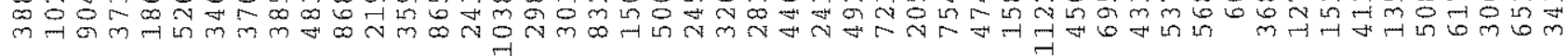

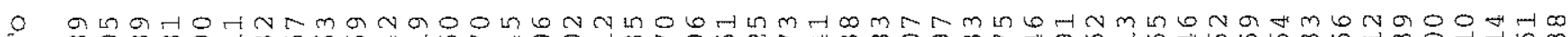
被

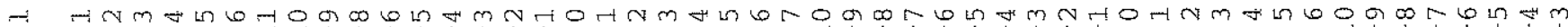

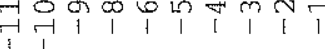

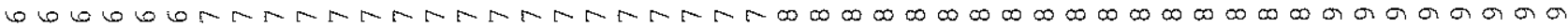

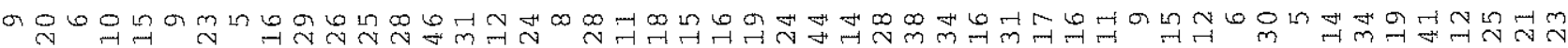

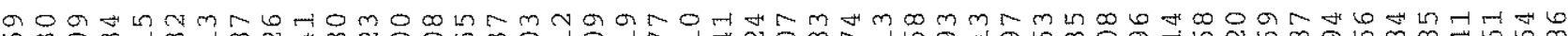
诲

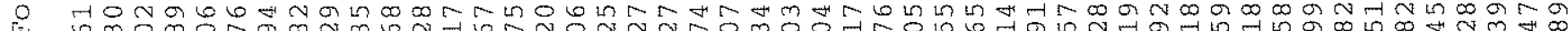

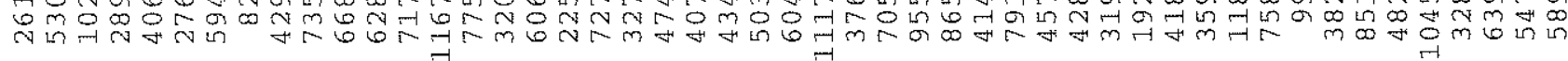
-1 nor

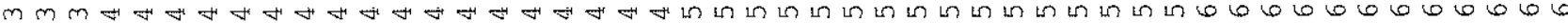


G U m

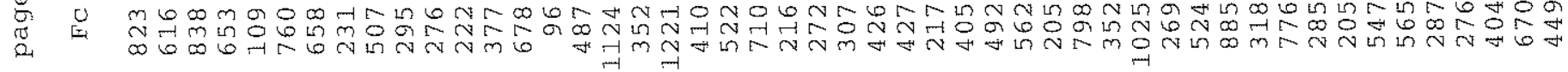

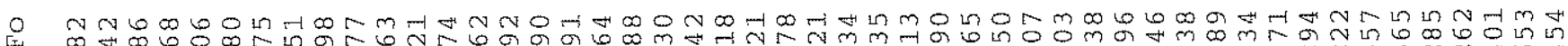
D

- MN

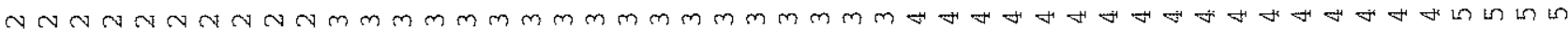

nn

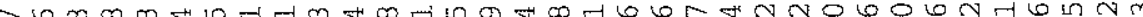
m

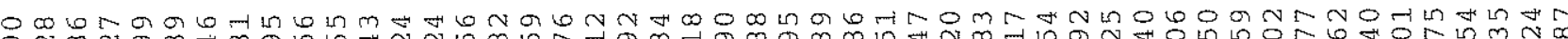

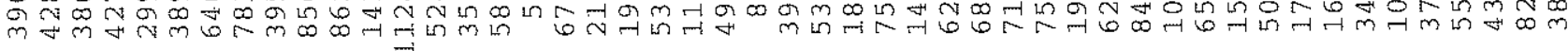

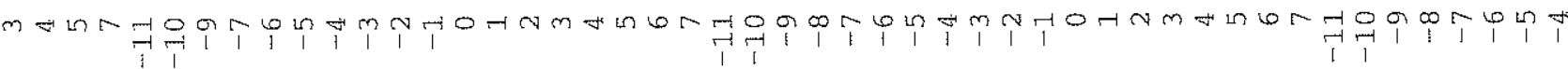
HHA 대

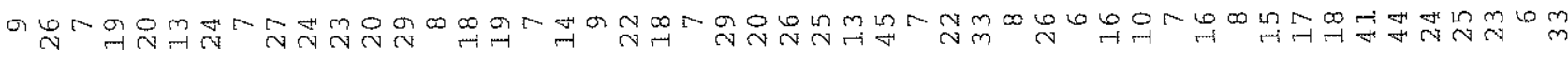

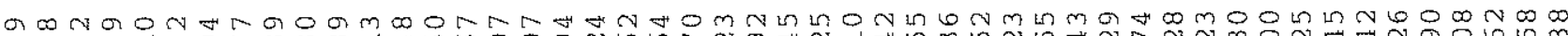
吕

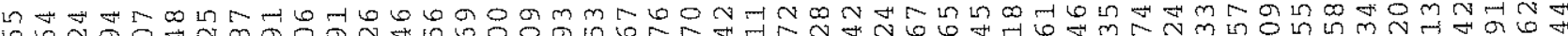

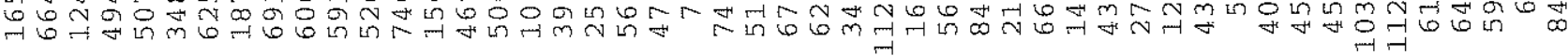

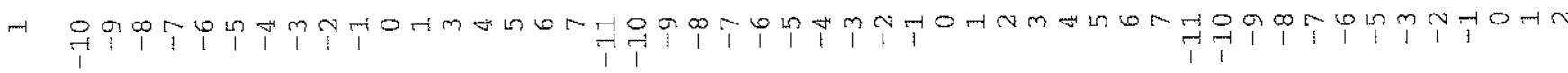

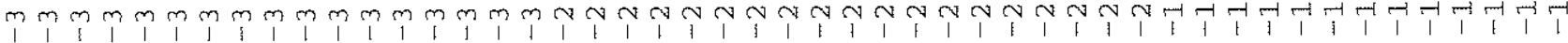
เ

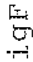

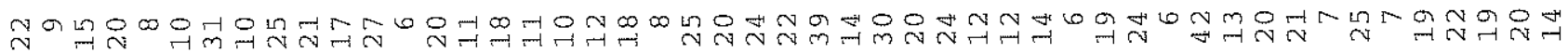

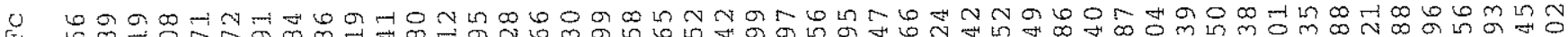

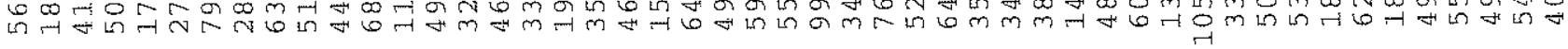

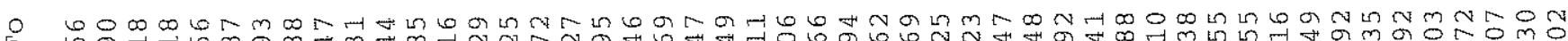

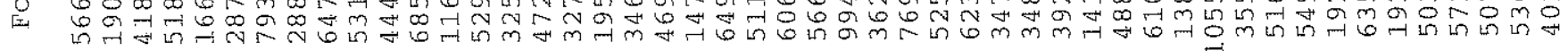

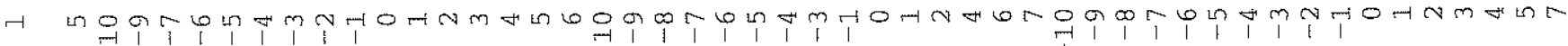

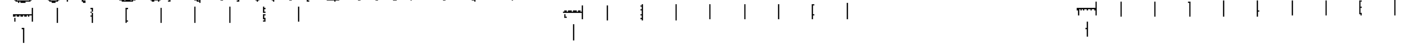

$\begin{array}{rlll}1 & 1\end{array}$ I I แ

Sis

ᄋ แ

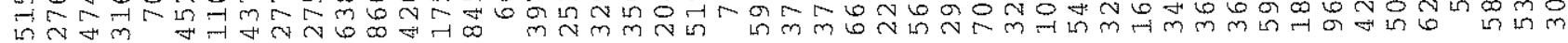

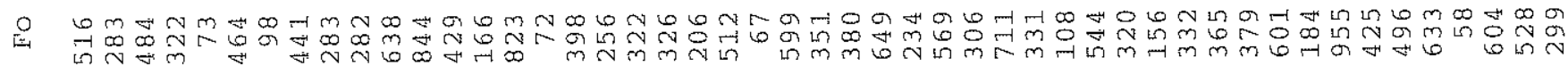
$\rightarrow$ OHNm

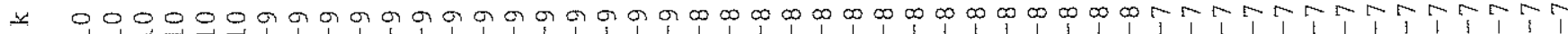

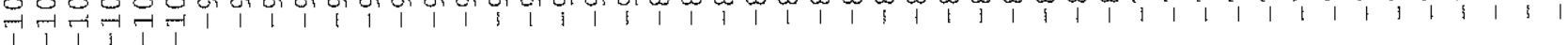

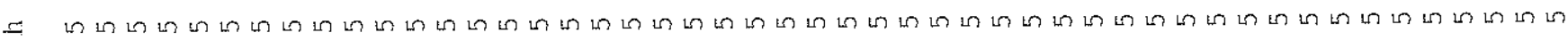




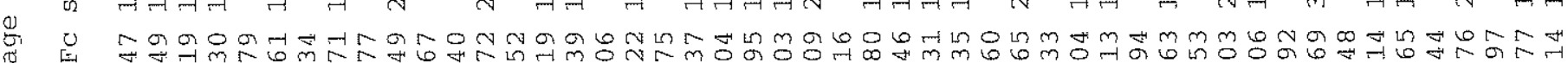

至

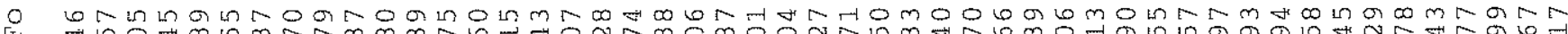

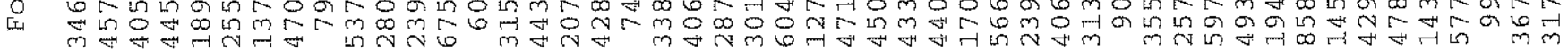

- N

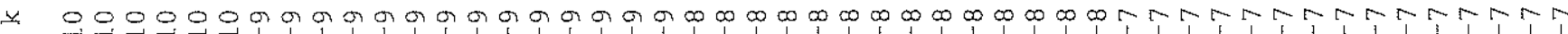

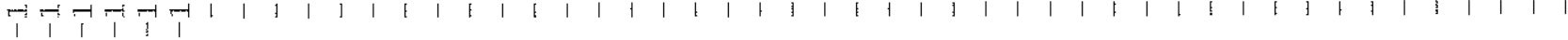

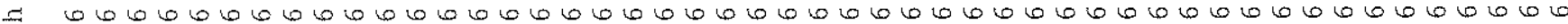

留

மm

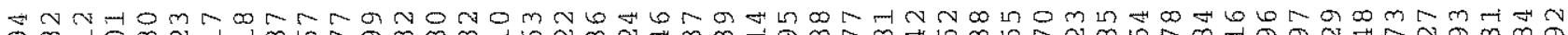

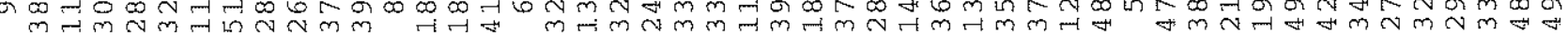

O

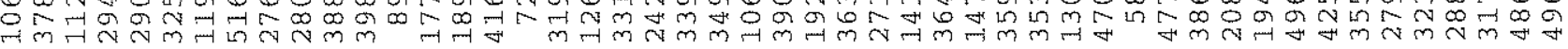

- mNHO

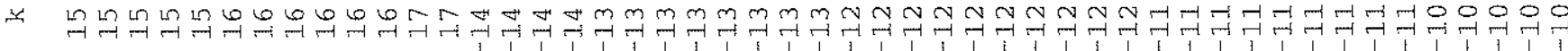

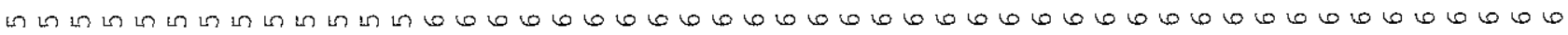

琵

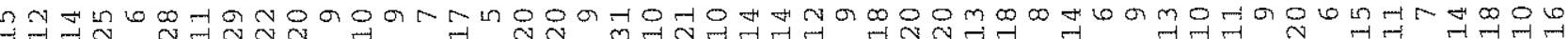

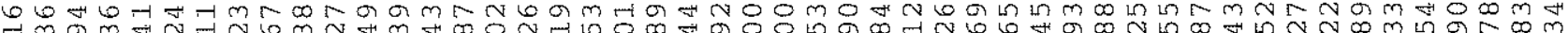
当

- \# 펌

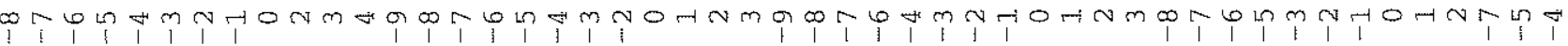

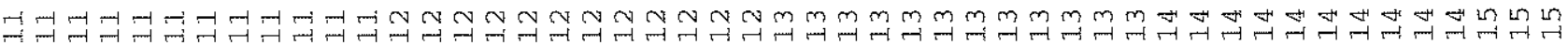

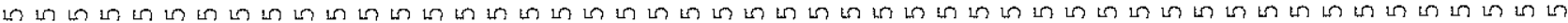

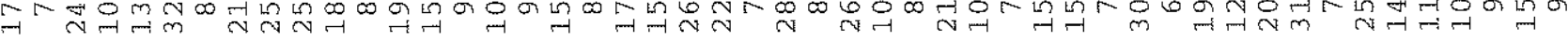

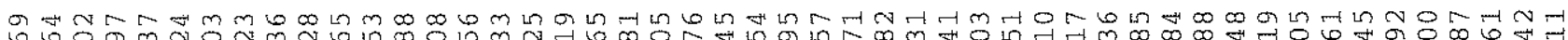
母.

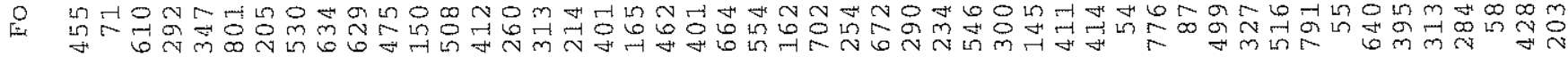

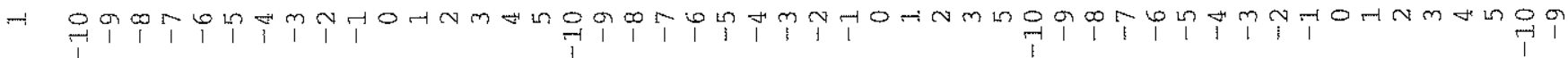

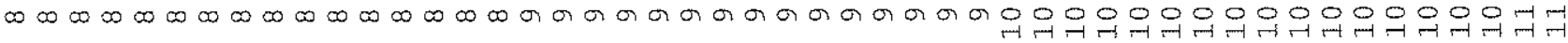

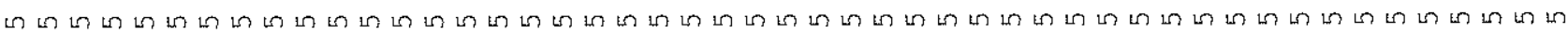

の NG

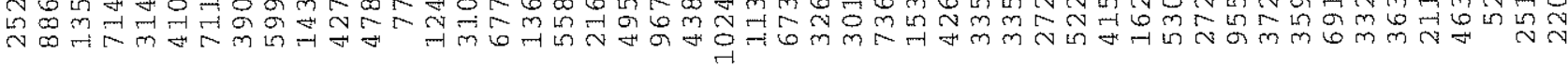

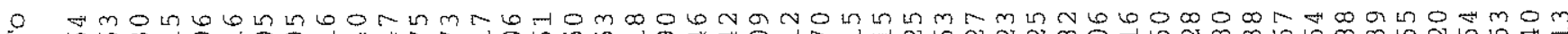

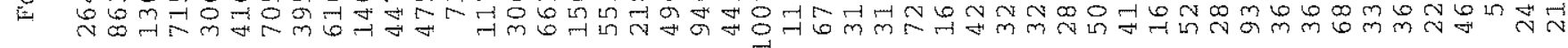

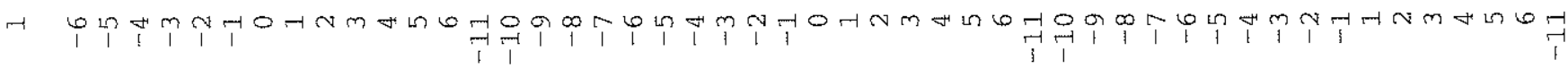
צ L L If 


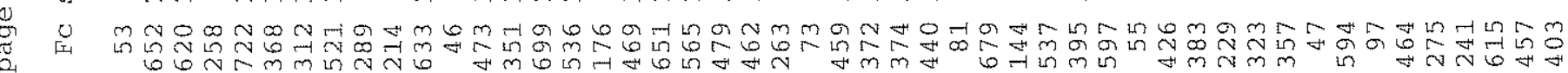

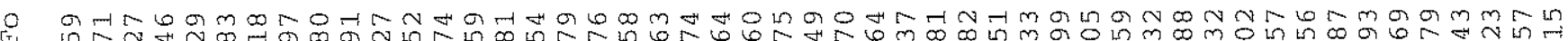

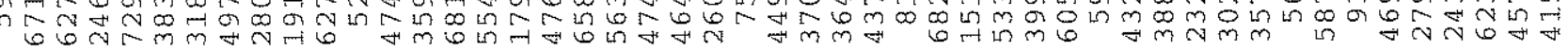

m l

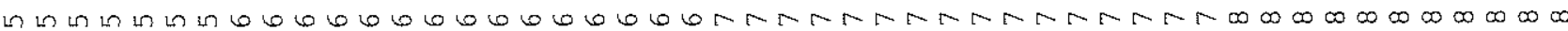

$=6060606066666660666660666666666666666666660666666$

要

क्न Nom m N

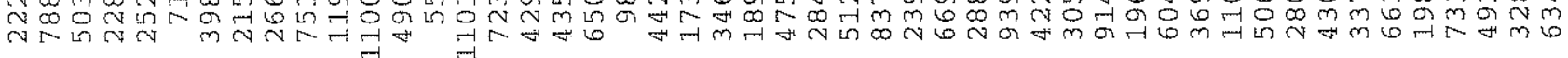

O \#

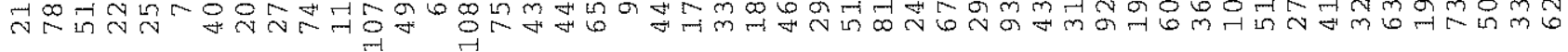
HN

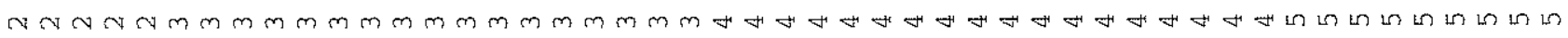

ص م

[x]

G Uत

- mm-

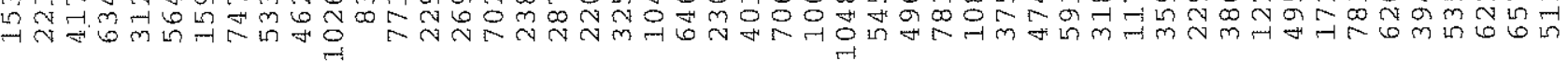
以

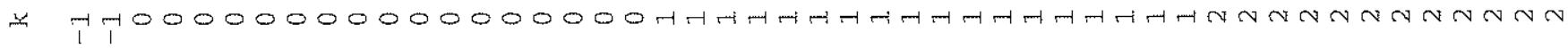

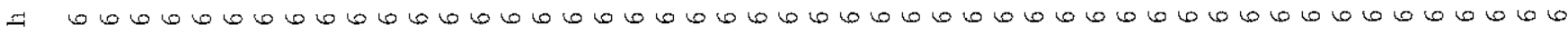

II

ம

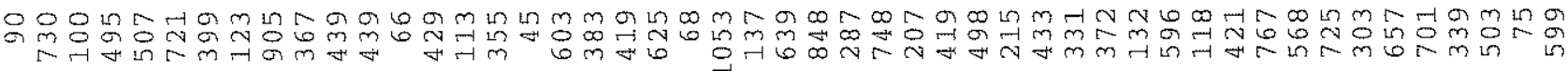

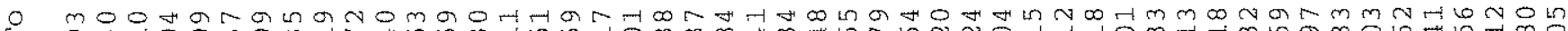
I

- का l

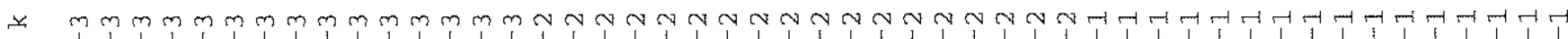
$=\quad$ "

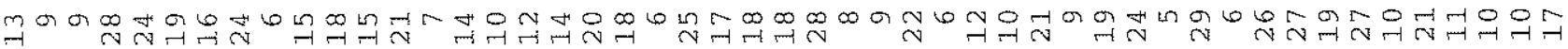

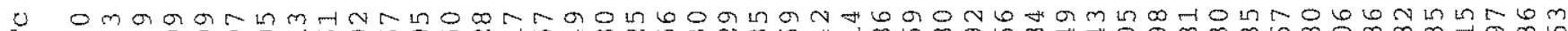

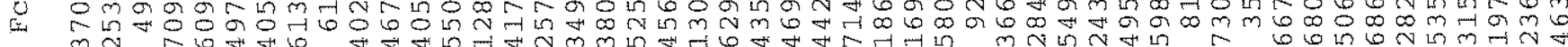

- एल m

每 ت 
g U NOFம 焉

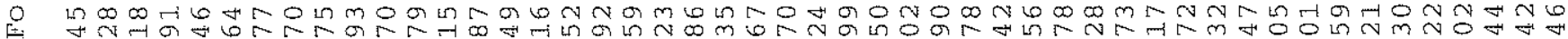

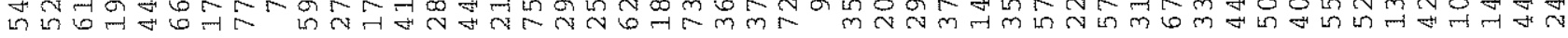

- Tि⿴囗十

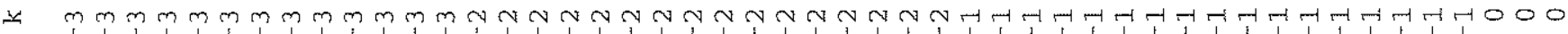

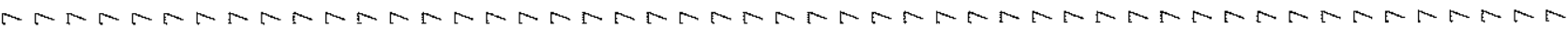

का

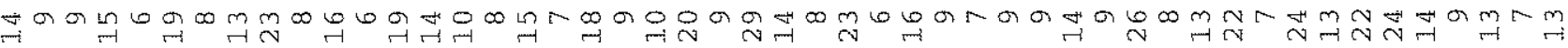
ம

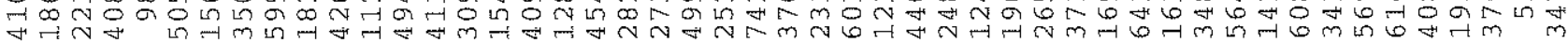

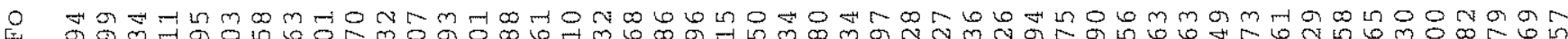

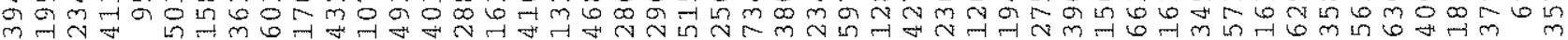

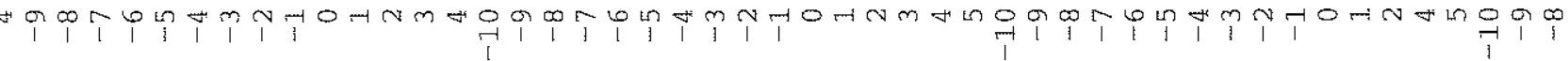

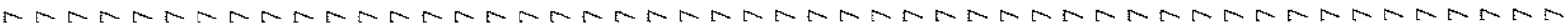

㫨

애색

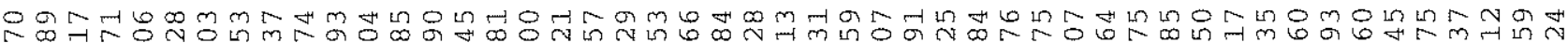
त

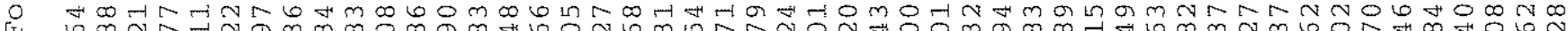

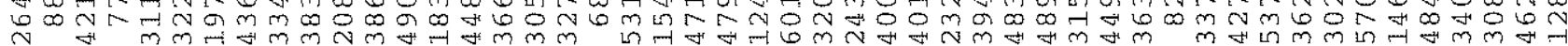

-

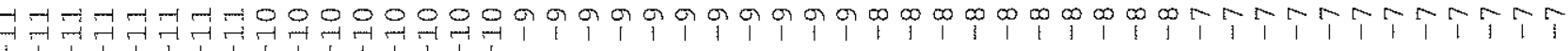

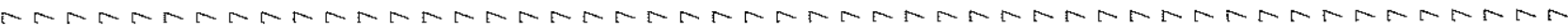

(5)

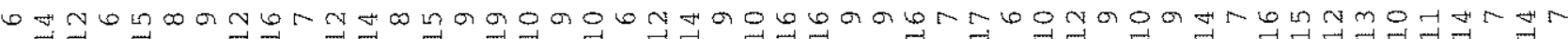

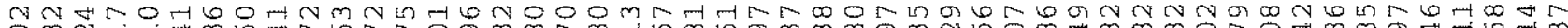

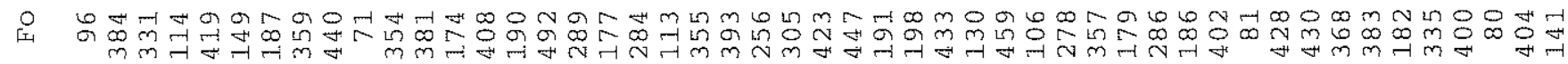

H M

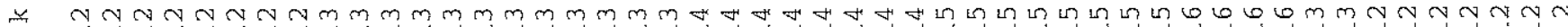

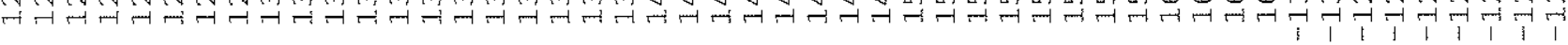

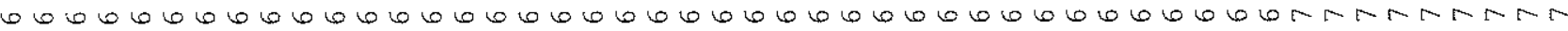

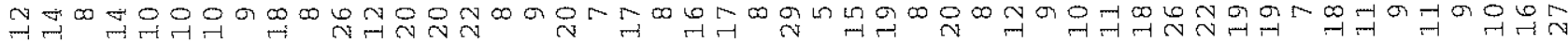
u H. Wmon 헤

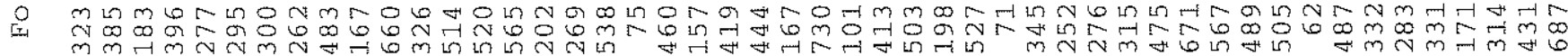

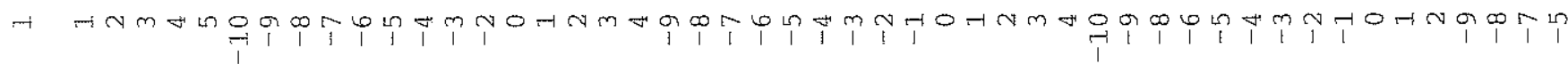

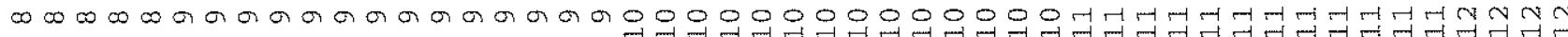


G $\quad$ L

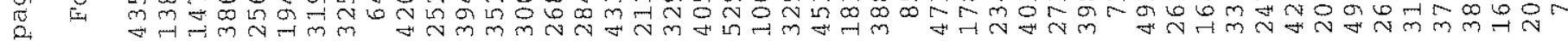

O の m出出

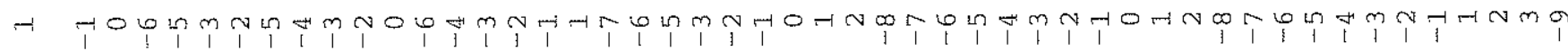

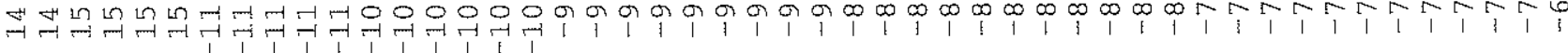
IN-NR

तु)

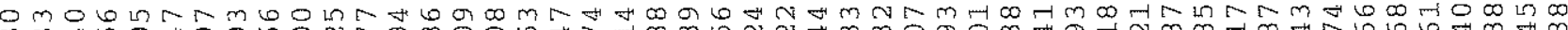
붑

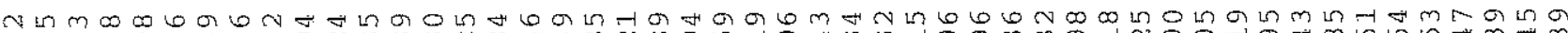
슴

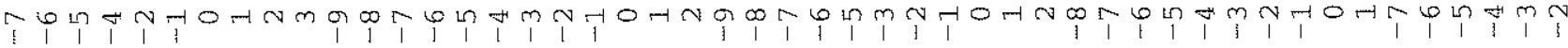

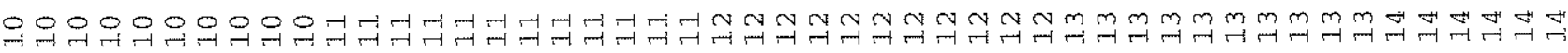

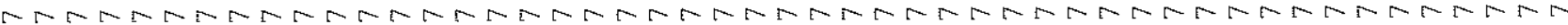

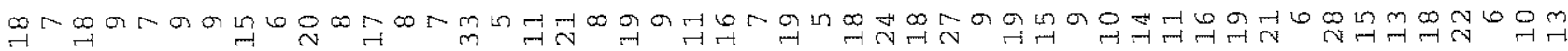
1 न

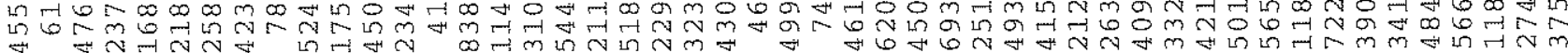

$6 m$ m

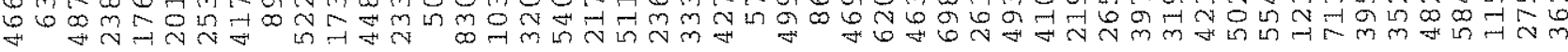
O-

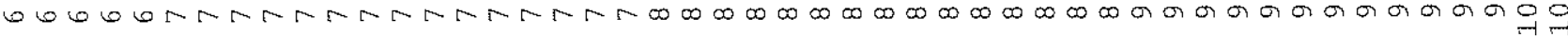

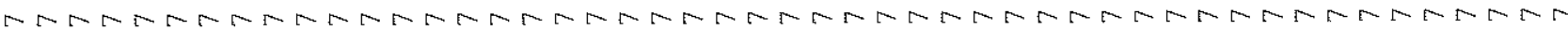

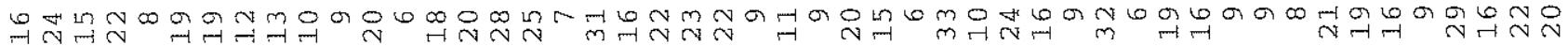

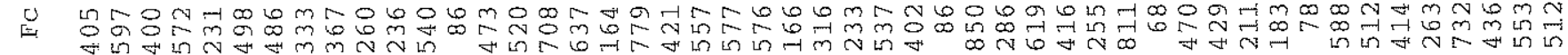

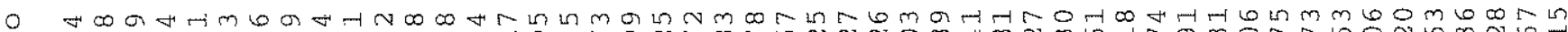
प m

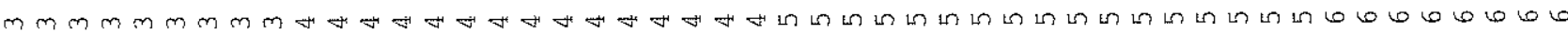

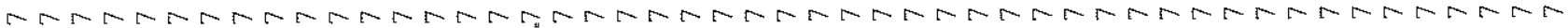

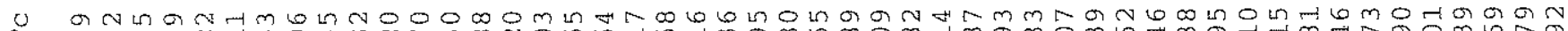
t.

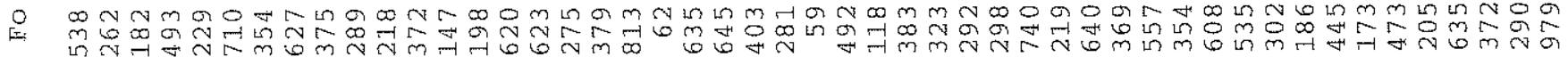
-

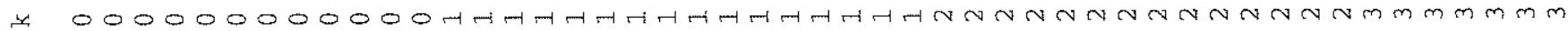


90 "

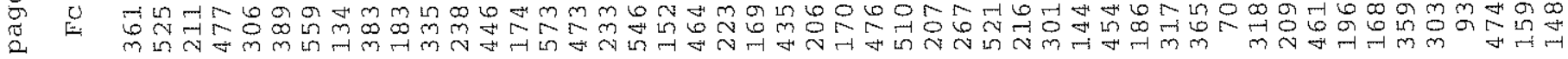

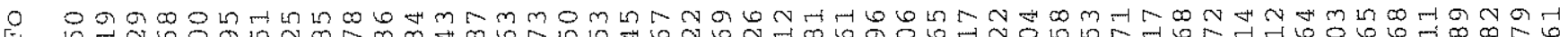
m

न Nकी

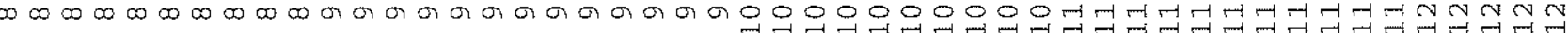

窝

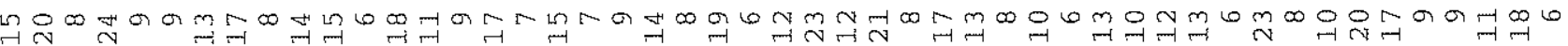

U

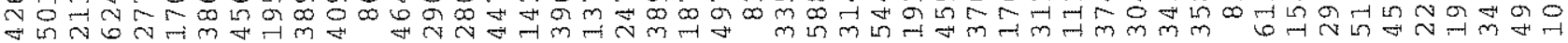

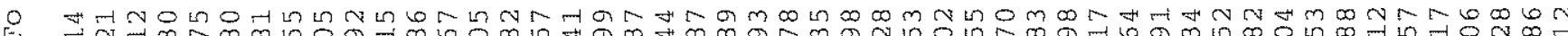

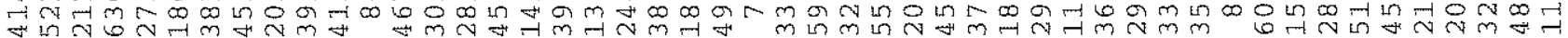
-1 य甘木

急

तु H⿻

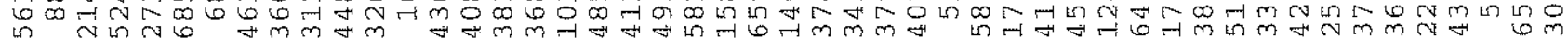

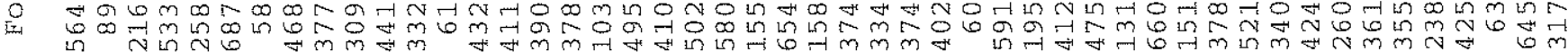

$\rightarrow$ Tim

எ

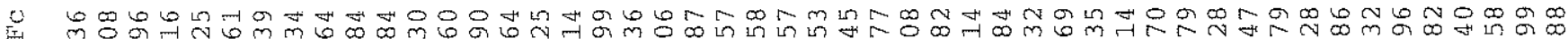
N

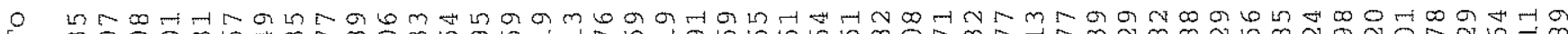
死

- HNm

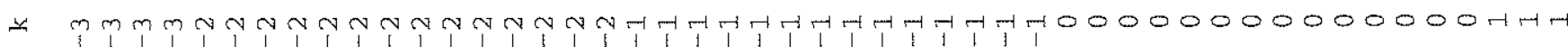

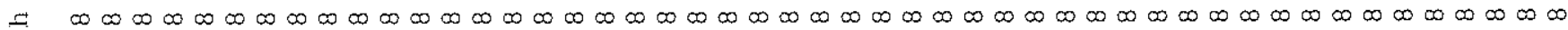
臣

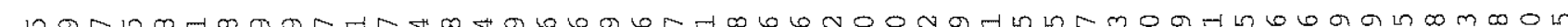
प्न L्र

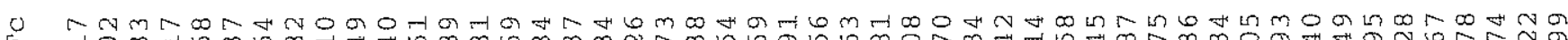

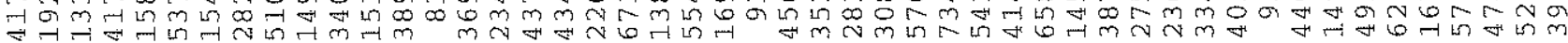

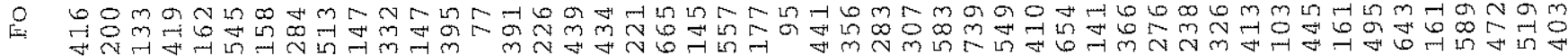

近

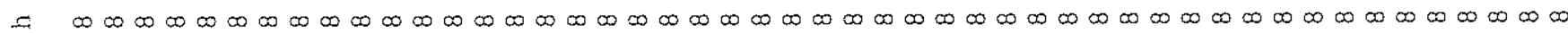




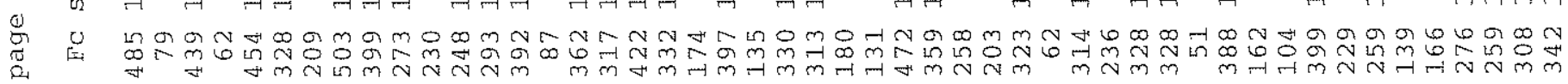

달 감

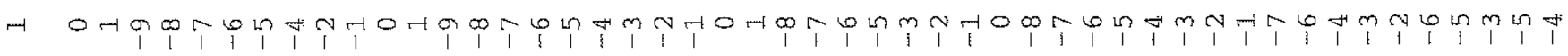

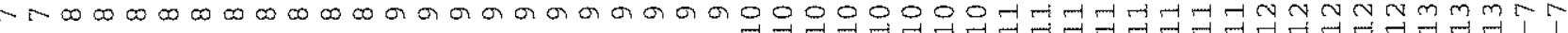

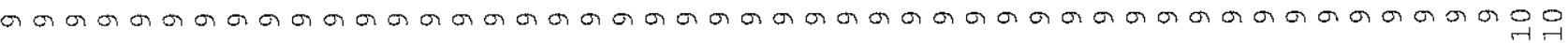

m

O N

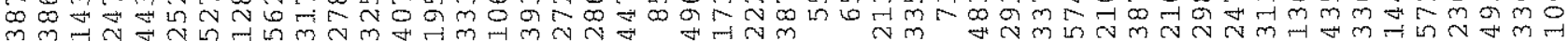

E OND

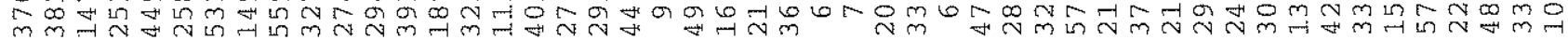

No m

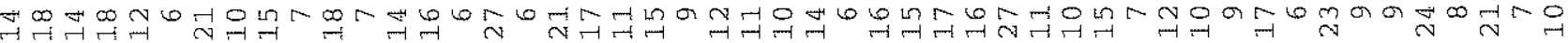
U DONMm-10

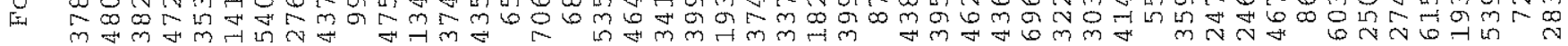

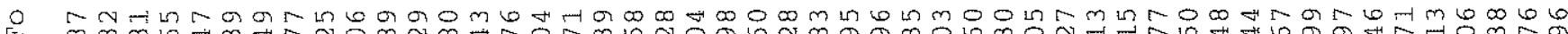
m

$\rightarrow$ m m

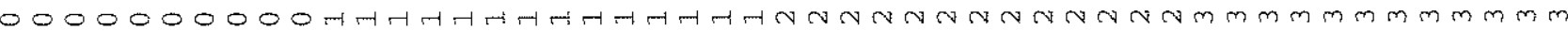

엄유 늘

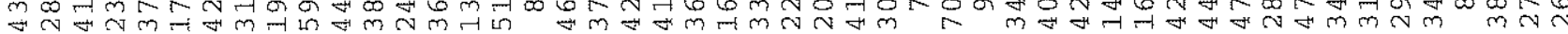

- manmN

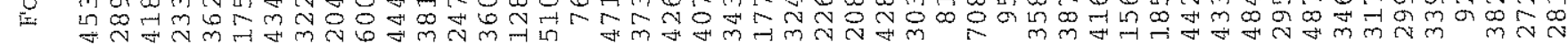

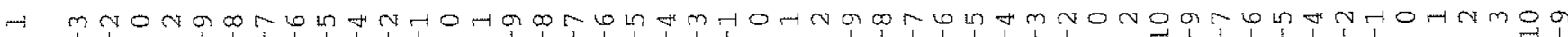
mín丨

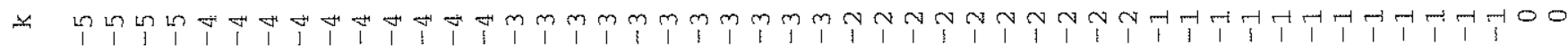

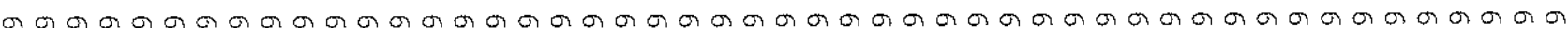

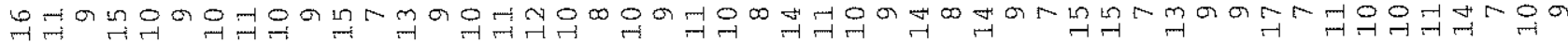

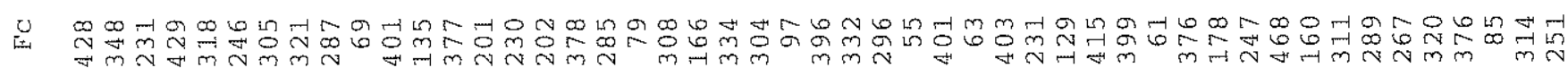

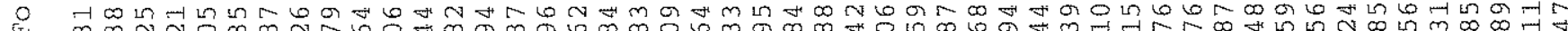
m

-

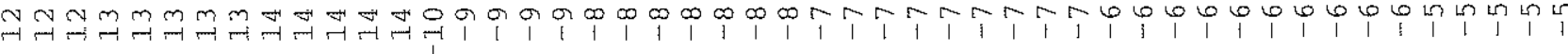


ब

O HLU HLN

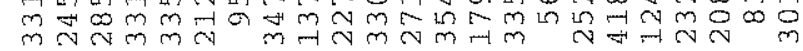
li

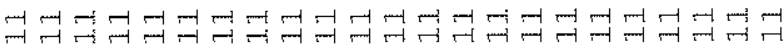

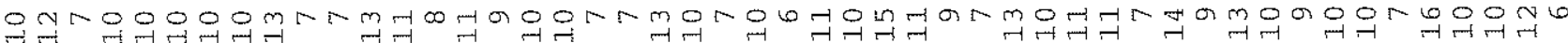

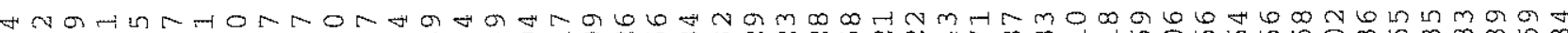
宁

mNmNOOHLHG

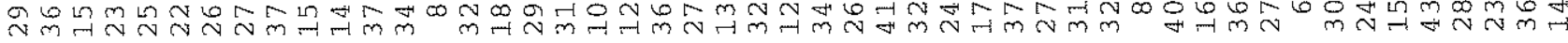
अ5 -1 HW

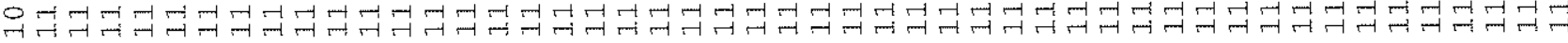

$\frac{5+1}{6}$

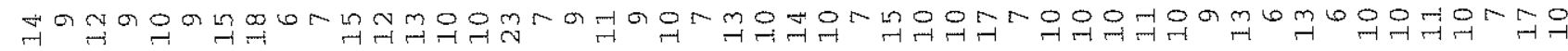

에

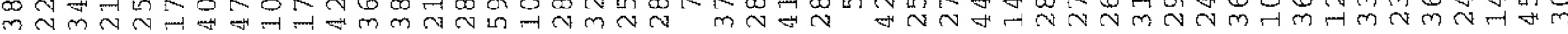

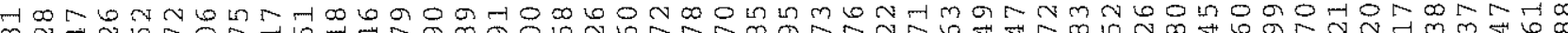
m

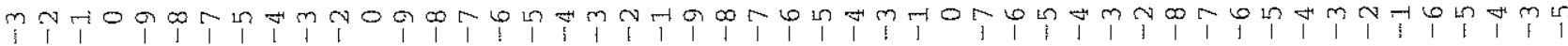

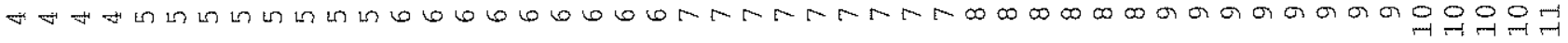

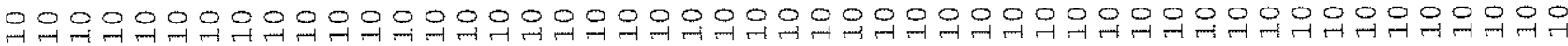

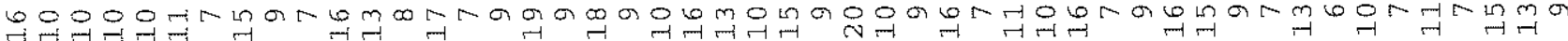

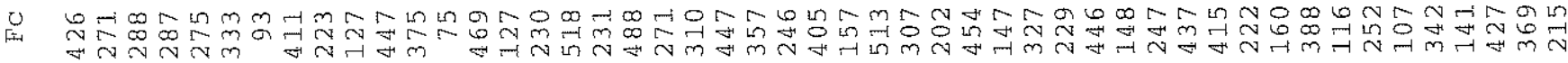

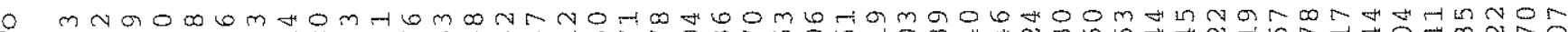

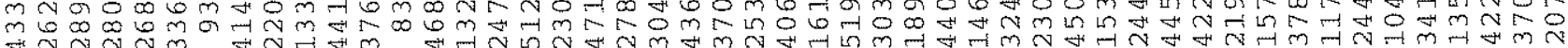
ongon

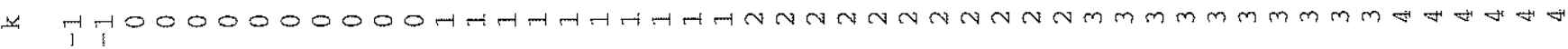

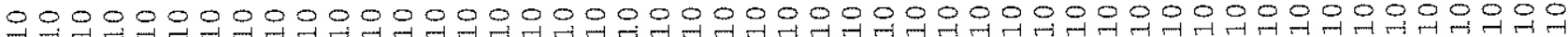

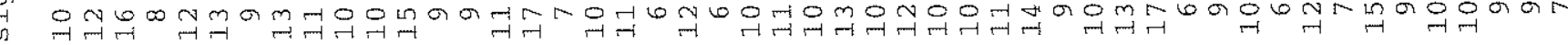
U तN

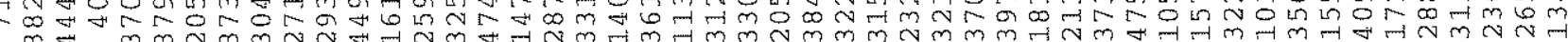
O

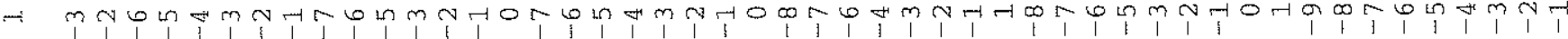

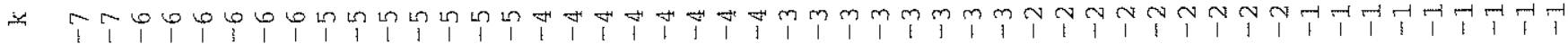

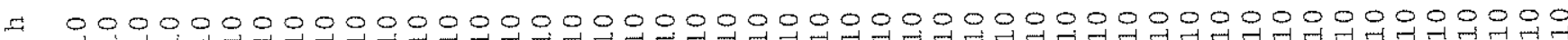

